$\underline{\text { Supporting Information }}$

\title{
One-Step Approach to Polyester-Polyether Block Copolymers Using Highly Tunable Bicomponent Catalyst
}

\author{
Heng Li, Guanchen He, Ye Chen, Junpeng Zhao*, and Guangzhao Zhang \\ Faculty of Materials Science and Engineering, South China University of Technology, Guangzhou \\ 510641, China
}

\section{Experimental Section}

\section{Chemicals}

Tetrahydrofuran (THF; Guangzhou Chemical Reagent, AR) was successively dried over molecular sieve ( $4 \AA$ ) and calcium hydride $\left(\mathrm{CaH}_{2}\right)$ before distilled. Propylene oxide (PO; Aldrich, $\left.99 \%\right)$ was stirred with sodium hydride $(\mathrm{NaH})$ overnight at room temperature $(\mathrm{RT})$, then vacuum-transferred into a storage flask. Ethylene oxide (EO; Aldrich, 99\%) was condensed from a metal cylinder into a graduated cylindrical flask pre-charged with $\mathrm{NaH}$ by cooling the flask at $0{ }^{\circ} \mathrm{C}$ under vacuum, stirred with $\mathrm{NaH}$ at $0{ }^{\circ} \mathrm{C}$ for $4 \mathrm{~h}$, then vacuum-transferred into the reaction flask. EO is volatile, potentially explosive, and toxic by inhalation. We thus recommend that all the glassware used for 
purification and reaction of EO should be strictly air tight, and that purified EO should be completely transferred into the reaction flask and completely reacted therein before the reaction flask is opened up. great caution in the process of handling EO. Benzyl alcohol (BA; Aladdin, 99\%) was stirred with $\mathrm{CaH}_{2}$ overnight and vacuum-distilled. Pentaerythritol (PT; Aladdin, 99\%) and 1,4benzenedimethanol (BDM; Aladdin, 99\%) were dried by azeotropic distillation of THF prior to use. Phthalic anhydride (PA; Aladdin, 99\%) was first sublimated under vacuum, then dissolved in acetic anhydride and stirred at $80{ }^{\circ} \mathrm{C}$ overnight before recrystallized at RT. Acetic acid (AcOH; Aladdin, 99\%), triethylborane ( $\mathrm{Et}_{3} \mathrm{~B}, \quad$ Aladdin, $1.0 \mathrm{M}$ in $\mathrm{THF}$ ) and tert-butyliminotris(dimethylamino)phosphorane ( $t$-BuP 1 ; Aldrich, 97\%) were used as received.

\section{Instrumentation}

NMR spectra were recorded at RT on a Bruker AV600 NMR spectrometer using $\mathrm{CDCl}_{3}$ as the solvent and tetramethylsilane as the internal standard. Monomer conversion was calculated from

the ${ }^{1} \mathrm{H}$ NMR spectrum of the crude product by comparison of the integrals of a characteristic signal from the remaining monomer and the corresponding signal from the copolymer. Number-average molar mass $\left(M_{\mathrm{n}, \mathrm{NMR}}\right)$ of the isolated copolymer was calculated from the ${ }^{1} \mathrm{H}$ NMR spectrum by comparison of the integrals of signals from the end group and polymer main body.

Size exclusion chromatography (SEC) coupled with refractive index (RI) and UV detectors was conducted in $N, N$-dimethylformamide (DMF) with $\operatorname{LiBr}(0.05 \mathrm{M})$ at $50{ }^{\circ} \mathrm{C}$ and a flow rate of 1.0 $\mathrm{mL} \min ^{-1}$ using three successively connected Styragel columns (HR2, HR4, HR6) for the EOderived copolymers. A series of narrowly dispersed polystyrene (PS) standards were used for calibration to obtain apparent number-average molar mass $\left(M_{\mathrm{n}, \mathrm{SEC}}\right)$ and molar mass distribution $\left(\oslash_{\mathrm{M}}\right)$ of the copolymers. For PO-derived copolymers, SEC coupled with successively connected RI 
and UV detectors was conducted in THF at $35^{\circ} \mathrm{C}$ and the same flow rate using two identical PL gel columns (5 $\mu \mathrm{m}$, MIXED-C) and PS standards for calibration.

Dynamic light scattering (DLS) measurements were performed at RT on a DelsaNano C particle and zeta potential analyser (Beckman Coulter) to obtain the average hydrodynamic radius $\left(R_{\mathrm{h}}\right)$ of the nanoaggregates formed by the block copolymers in selective solvents. The measured solution was prepared by dissolving a known amount of the copolymer at RT in water, ethanol, or ethanolwater mixture to afford a copolymer concentration of $10.0 \mathrm{mg} \mathrm{mL}^{-1}$.

Differential scanning calorimetry (DSC) measurements were performed on a NETZSCH DSC204F1 system in a nitrogen flow. The sample was heated to $150{ }^{\circ} \mathrm{C}$ at a heating rate of $10{ }^{\circ} \mathrm{C}$ $\min ^{-1}$, kept at this temperature for 5 min to remove thermal history, cooled to $-150{ }^{\circ} \mathrm{C}$ at a cooling rate of $10{ }^{\circ} \mathrm{C} \mathrm{min}^{-1}$, kept at this temperature for $10 \mathrm{~min}$, and then heated again to $150{ }^{\circ} \mathrm{C}$ at a heating rate of $10{ }^{\circ} \mathrm{C} \mathrm{min}^{-1}$. The glass transition temperature $\left(T_{\mathrm{g}}\right)$ was acquired on the second heating run of a DSC measurement.

Atomic force microscope (AFM) images were acquired on an XE-100 AFM (Park Systems) in air. The copolymer thin film was formed on a glass surface by spin-coating of a toluene solution (5.0 $\mathrm{mg} \mathrm{mL} \mathrm{m}^{-1}$ ). The film was then annealed at $80{ }^{\circ} \mathrm{C}$ for $4 \mathrm{~h}$ and slowly cooled down to RT. The surface morphology was obtained in tapping mode with an NCHR cantilever.

\section{Copolymerization Procedures}

Copolymerization of PA and PO. A typical procedure for PAPO-2 (Table 1) is given as follows. PA $(0.74 \mathrm{~g}, 5.0 \mathrm{mmol})$ and BDM $(6.9 \mathrm{mg}, 0.05 \mathrm{mmol})$ were charged in a round-bottom reaction flask equipped with a Teflon Stopcock and dissolved in purified THF, followed by slow removal of THF by vacuum-distillation. Then $\mathrm{PO}(3.49 \mathrm{~mL}, 50.0 \mathrm{mmol})$ was added and the mixture was magnetically stirred at RT until PA dissolved completely. After that, $t$ - $\mathrm{BuP}_{1}(11.7 \mu \mathrm{L}, 0.05 \mathrm{mmol})$ 
and $\mathrm{Et}_{3} \mathrm{~B}(25.0 \mu \mathrm{L}, 0.025 \mathrm{mmol})$ were added in a glovebox $\left([\mathrm{PA}]_{0}=1.4 \mathrm{M},[\mathrm{PO}]_{0}=14.0 \mathrm{M}\right)$ to start the copolymerization. Small aliquots (ca. $0.05 \mathrm{~mL}$ each) were withdrawn at different time intervals, injected into $\mathrm{CDCl}_{3}(0.6 \mathrm{~mL}$, containing 1 drop of $\mathrm{AcOH})$, and used for ${ }^{1} \mathrm{H} \mathrm{NMR}$ analysis to determine the conversion of $\mathrm{PA}$ and $\mathrm{PO}$. The $\mathrm{CDCl}_{3}$ solution was further diluted with THF for SEC analysis to determine $M_{\mathrm{n}, \mathrm{SEC}}$ and $\bigoplus_{\mathrm{M}}$ of the copolymer. After the reaction mixture was stirred at RT for $24 \mathrm{~h}$, AcOH (1 mL) was added for quenching and a small aliquot was withdrawn for ${ }^{1} \mathrm{H}$ NMR and SEC analysis. The crude product was diluted with THF, precipitated in water, collected, and dried in vacuum to afford a white paste. Conv. $(\mathrm{PA})=100 \%$, Conv. $(\mathrm{PO})$ in the formation of $\mathrm{PPO}=$ 84\%. Yield: $1.85 \mathrm{~g}(51 \%) . M_{\mathrm{n}, \mathrm{SEC}}=56.6 \mathrm{~kg} \mathrm{~mol}^{-1}, \bigoplus_{\mathrm{M}}=1.04 .{ }^{1} \mathrm{H} \mathrm{NMR}\left(600 \mathrm{MHz}, \mathrm{CDCl}_{3}\right)$ : $\delta / \mathrm{ppm}=7.76-7.40\left(-\mathrm{OCOC}_{6} \mathrm{H}_{4} \mathrm{OCO}-\right.$ derived from $\left.\mathrm{PA}\right), 7.36\left(-\mathrm{OCH}_{2} \mathrm{C}_{6} \mathrm{H}_{4} \mathrm{CH}_{2} \mathrm{O}-\right.$ derived from BDM), 5.49-5.32 (- $\left.\mathrm{C}_{6} \mathrm{H}_{4} \mathrm{COOCH}_{2} \mathrm{CH}\left(\mathrm{CH}_{3}\right) \mathrm{OCO}^{-}\right), \quad 5.25 \quad\left(-\mathrm{OCH}_{2} \mathrm{C}_{6} \mathrm{H}_{4} \mathrm{CH}_{2} \mathrm{O}^{-}\right), \quad 4.48-4.29$

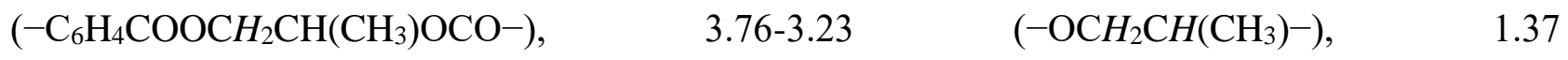
$\left({ }^{-} \mathrm{C}_{6} \mathrm{H}_{4} \mathrm{COOCH}_{2} \mathrm{CH}\left(\mathrm{CH}_{3}\right) \mathrm{OCO}-\right), 1.21-1.01\left(-\mathrm{OCH}_{2} \mathrm{CH}\left(\mathrm{CH}_{3}\right)^{-}\right) ; M_{\mathrm{n}, \mathrm{NMR}}=50.3 \mathrm{~kg} \mathrm{~mol}^{-1}$.

Copolymerization of PA and PO in the other entries of Table 1 and Table S1 was performed in a similar procedure except that different feed ratio of $\mathrm{PA}, \mathrm{PO}, \mathrm{BDM}, t-\mathrm{BuP}_{1}$, and $\mathrm{Et}_{3} \mathrm{~B}$ was used. For the experiments that used smaller amounts of PO (PAPO-4 and PAPO-S6 in Table 1), THF was added together with PO to help with the dissolution of PA $\left([\mathrm{PA}]_{0}=0.9 \mathrm{M},[\mathrm{PO}]_{0}=1.4 \mathrm{M}\right)$.

Copolymerization of PA and EO. A typical procedure for PAEO-1 (Table 1) is given as follows. PA $(0.74 \mathrm{~g}, 5.0 \mathrm{mmol})$ and $\mathrm{BDM}(6.9 \mathrm{mg}, 0.05 \mathrm{mmol})$ were charged in a round-bottom reaction flask equipped with a Teflon Stopcock and dissolved in purified THF, followed by slow removal of THF by vacuum-distillation. Then THF $(5.0 \mathrm{~mL}), t-\mathrm{BuP}_{1}(11.7 \mu \mathrm{L}, 0.05 \mathrm{mmol})$, and $\mathrm{Et}_{3} \mathrm{~B}(15.0 \mu \mathrm{L}$, $0.015 \mathrm{mmol}$ ) were added in a glovebox. After PA dissolved completely, the flask was docked on a vacuum line, and EO $(2.5 \mathrm{~mL}, 50.0 \mathrm{mmol})$ was slowly introduced by vacuum transfer at $0{ }^{\circ} \mathrm{C}$ 
$\left([\mathrm{PA}]_{0}=0.7 \mathrm{M},[\mathrm{EO}]_{0}=6.7 \mathrm{M}\right)$ to start the copolymerization. The reaction mixture was magnetically stirred at RT. At different time intervals, the reaction flask was cooled in an ice-water bath and small aliquots (ca. $0.05 \mathrm{~mL}$ each) were withdrawn in an argon flow, injected into $\mathrm{CDCl}_{3}$ (0.6 mL, containing 1 drop of $\mathrm{AcOH})$, and used for ${ }^{1} \mathrm{H}$ NMR analysis to determine the conversion of PA and EO. The $\mathrm{CDCl}_{3}$ solution was further diluted with $\mathrm{DMF}$ for SEC analysis to determine $M_{\mathrm{n}, \mathrm{SEC}}$ and $\bigoplus_{\mathrm{M}}$ of the copolymer. The reaction was finally quenched at $18 \mathrm{~h}$ by addition of $\mathrm{AcOH}$ (1 $\mathrm{mL}$ ) before a small aliquot was withdrawn for ${ }^{1} \mathrm{H}$ NMR and SEC analysis. The crude product was diluted with $\mathrm{CHCl}_{3}$, precipitated in diethyl ether, collected, and dried in vacuum to afford a white waxy solid. Conv.(PA) $=100 \%$, Conv.(EO) in the formation of PEO = 100\%. Yield: $2.2 \mathrm{~g}(75 \%)$. $M_{\mathrm{n}, \mathrm{SEC}}=117.3 \mathrm{~kg} \mathrm{~mol}{ }^{-1}, \bigoplus_{\mathrm{M}}=1.12 .{ }^{1} \mathrm{H}$ NMR $\left(600 \mathrm{MHz}, \mathrm{CDCl}_{3}\right): \delta / \mathrm{ppm}=7.76-7.42$ (- $\mathrm{OCOC}_{6} \mathrm{H}_{4} \mathrm{OCO}-$ derived from PA), $7.33\left(-\mathrm{OCH}_{2} \mathrm{C}_{6} \mathrm{H}_{4} \mathrm{CH}_{2} \mathrm{O}-\right.$ derived from $\left.\mathrm{BDM}\right), 5.24$ $\left(-\mathrm{OCH}_{2} \mathrm{C}_{6} \mathrm{H}_{4} \mathrm{CH}_{2} \mathrm{O}^{-}\right)$, 4.60-4.42 $\left(-\mathrm{C}_{6} \mathrm{H}_{4} \mathrm{COOCH}_{2} \mathrm{CH}_{2} \mathrm{OCO}-\right)$, 3.84-3.45 $\left(-\mathrm{OCH}_{2} \mathrm{CH}_{2}-\right)$; $M_{\mathrm{n}, \mathrm{NMR}}=$ $60.1 \mathrm{~kg} \mathrm{~mol}^{-1}$.

Copolymerization of PA and EO in the other entries of Table 1 was performed in a similar procedure except that different amounts of EO and/or different initiators (dihydroxy BDM, monohydroxy BA, or tetrahydroxy PT) were used. 
Table S1. General Scheme, Conditions, and Selected Results of Copolymerization of PA and PO ${ }^{a}$

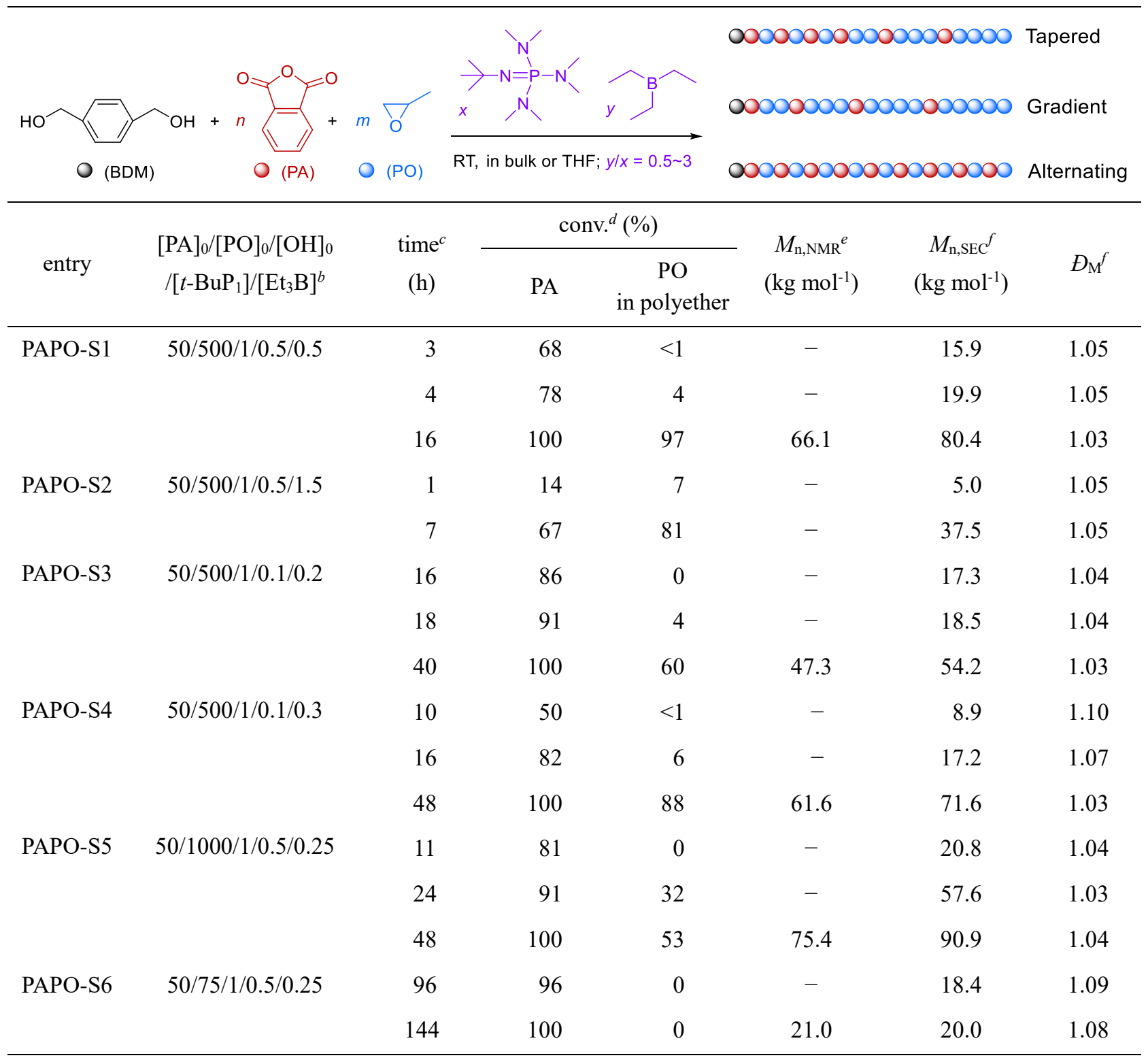

${ }^{a}$ Performed in bulk or THF (only PAPO-S6) with BDM as the initiator and [PA $]_{0}$ being $0.7 \sim 1.4 \mathrm{M}$. The copolymerized monomers are indicated in the entry names. ${ }^{b}$ Molar feed ratio of $\mathrm{PA}, \mathrm{PO}$, hydroxyl, $t$ - $\mathrm{BuP}_{1}$, and $\mathrm{Et}_{3} \mathrm{~B}$. ${ }^{c} \mathrm{Selected}$ reaction times of each copolymerization entry. ${ }^{d}$ Conversion of PA calculated by the integrals of the aromatic protons of PA and $\mathrm{P}\left(\mathrm{PA}-\right.$ alt-PO) in ${ }^{1} \mathrm{H}$ NMR spectrum, and conversion of PO in the formation of PPO calculated by the integrals of ether protons of PO and PPO (Figure S1). ${ }^{e}$ Calculated from ${ }^{1} \mathrm{H}$ NMR spectrum of the isolated product by comparison of signal integrals of the end group $\left(-\mathrm{C}_{6} \mathrm{H}_{4} \mathrm{CH}_{2} \mathrm{O}-\right)$ and copolymer main body. ${ }^{f}$ Apparent number-average molar mass and molar mass distribution obtained from SEC analysis (THF, $35^{\circ} \mathrm{C}$, PS standards). 

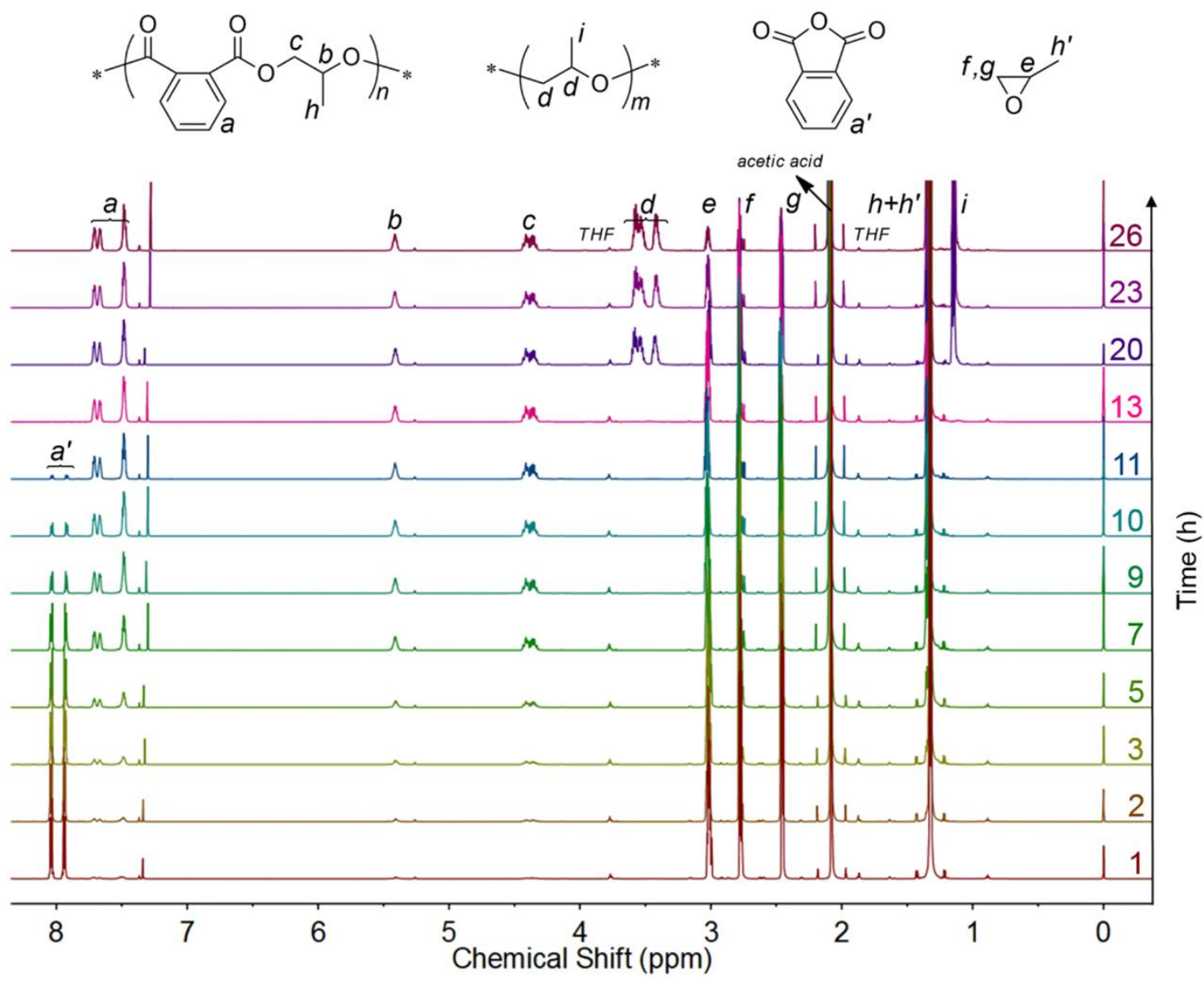

Figure S1. ${ }^{1} \mathrm{H}$ NMR spectra of the aliquots withdrawn at different reaction times from the copolymerization of PA and PO performed in bulk at RT with BDM as the initiator and the feed ratio of $[\mathrm{PA}]_{0} /[\mathrm{PO}]_{0} /[\mathrm{OH}]_{0} /[t-$ $\left.\mathrm{BuP}_{1}\right] /\left[\mathrm{Et}_{3} \mathrm{~B}\right]$ being $50 / 500 / 1 / 0.5 / 0.15$ which leads to a PPO- $b$-P(PA-alt-PO)- $b$-PPO triblock copolymer (PAPO-1 in Table 1). Conversions of PA and PO in Table 1 are calculated as $a /\left(a+a^{\prime}\right)$ and $d /(d+3 e)$. 

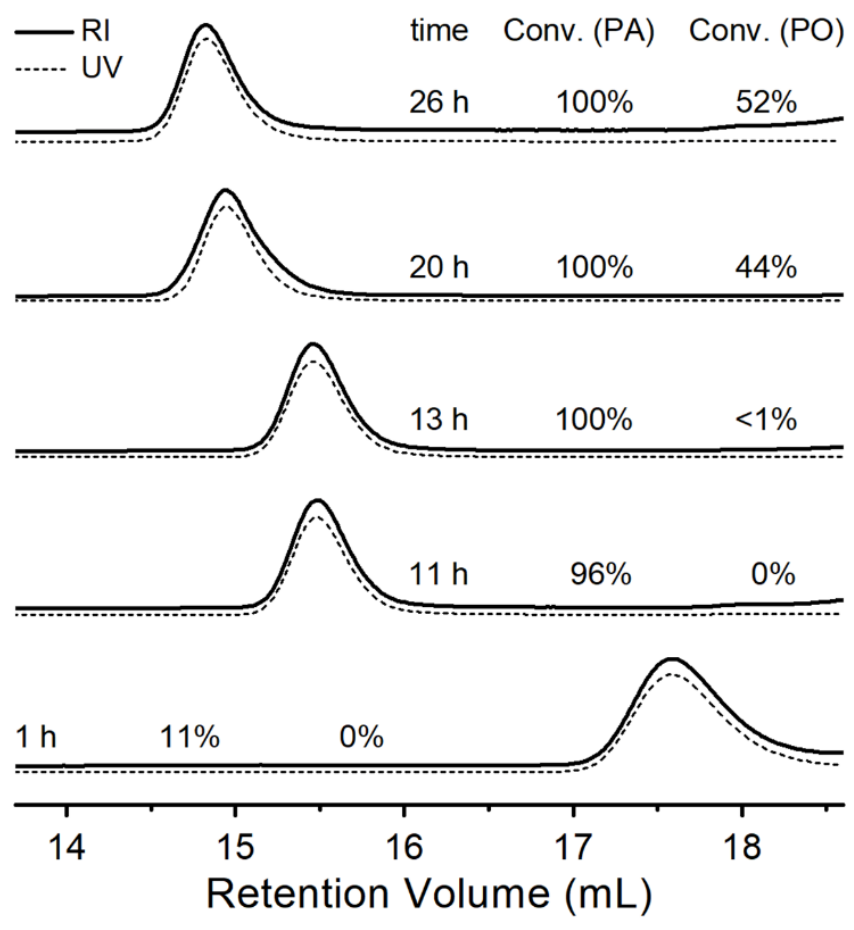

Figure S2. SEC traces (RI and UV responses) of the representative aliquots withdrawn at different reaction times from the copolymerization of PA and PO with BMD as the initiator (PAPO-1 in Table 1).

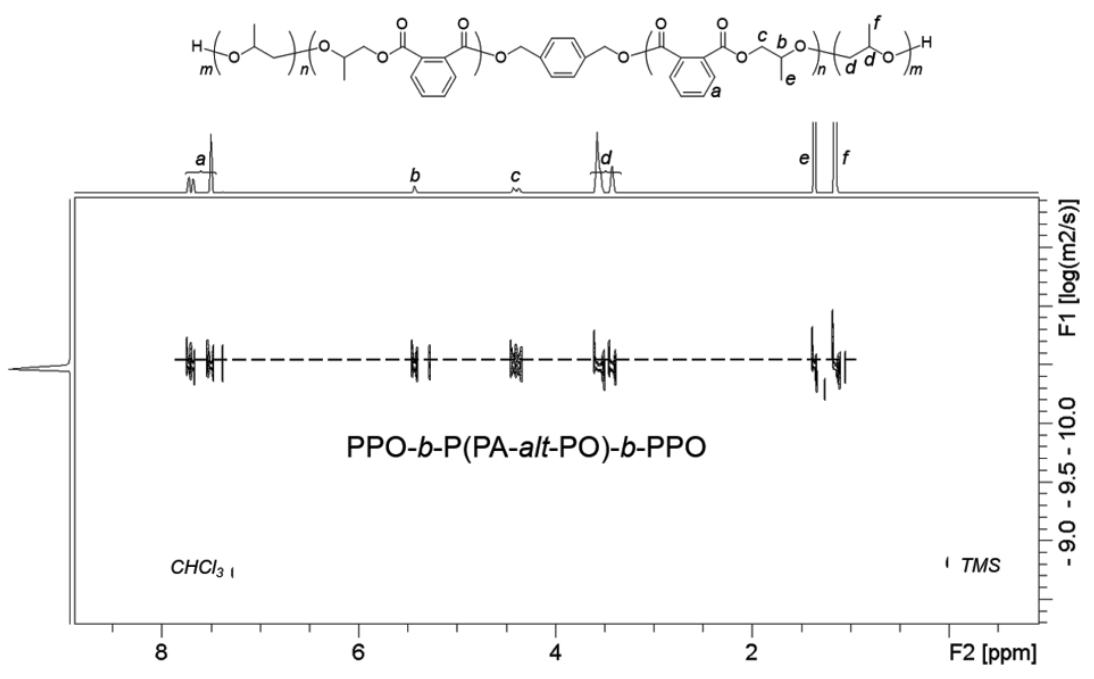

Figure S3. DOSY ${ }^{1} \mathrm{H}$ NMR spectrum of the isolated PPO- $b$-P(PA-alt-PO)- $b$-PPO triblock copolymer onestep synthesized from a mixture of PA and PO with BDM as the initiator (the product of PAPO-1 in Table 1). 

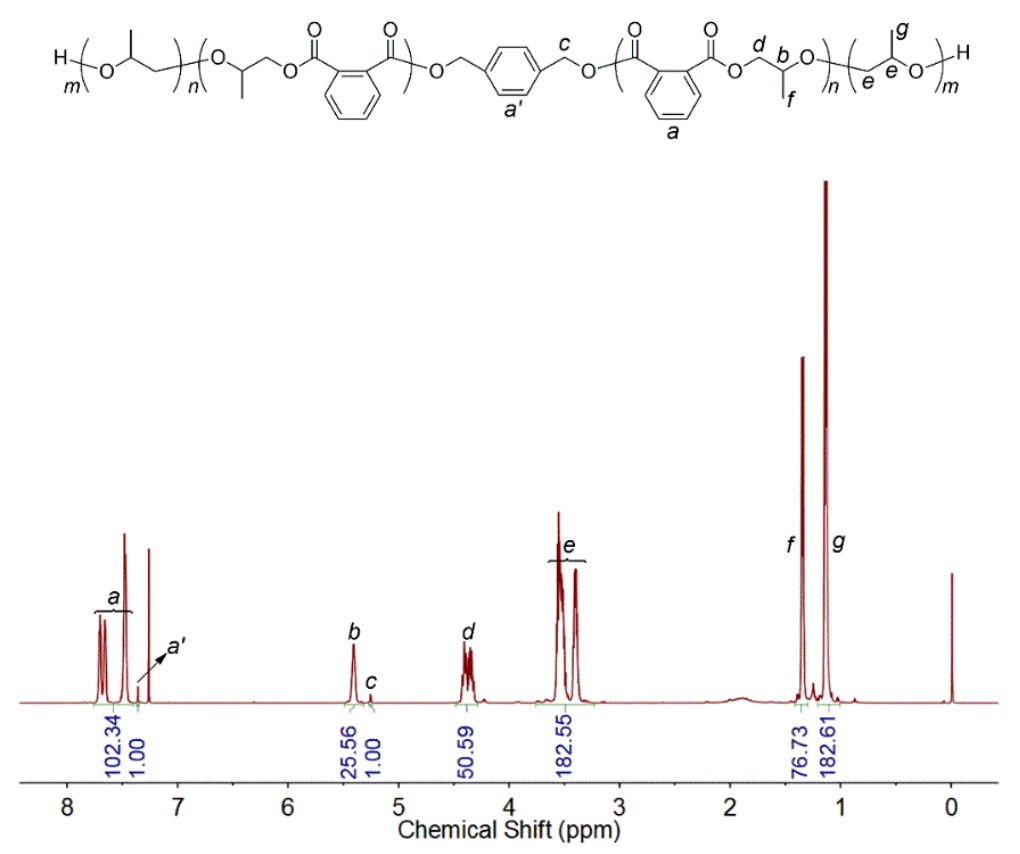

Figure S4. ${ }^{1} \mathrm{H}$ NMR spectrum of the isolated PPO- $b$-P(PA-alt-PO)- $b$-PPO triblock copolymer one-step synthesized from a mixture of PA and PO with BDM as the initiator (the product of PAPO-1 in Table 1).
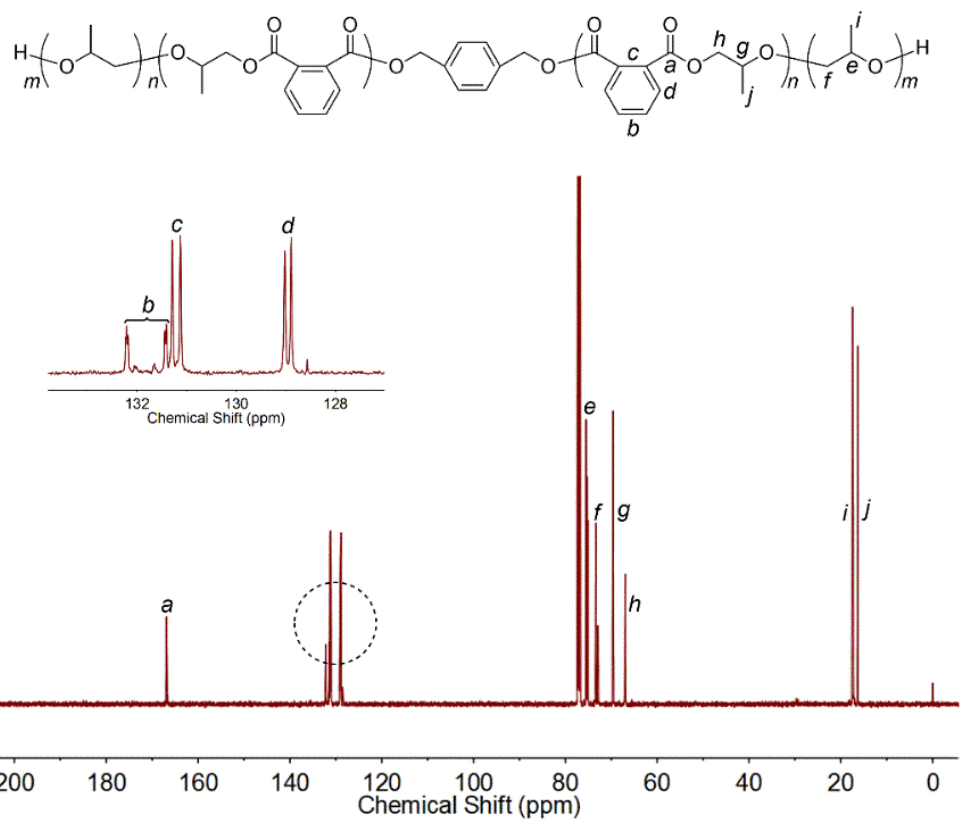

Figure S5. ${ }^{13} \mathrm{C}$ NMR spectrum of the isolated PPO- $b$-P(PA-alt-PO)- $b$-PPO triblock copolymer one-step synthesized from a mixture of PA and PO with BDM as the initiator (the product of PAPO-1 in Table 1). 


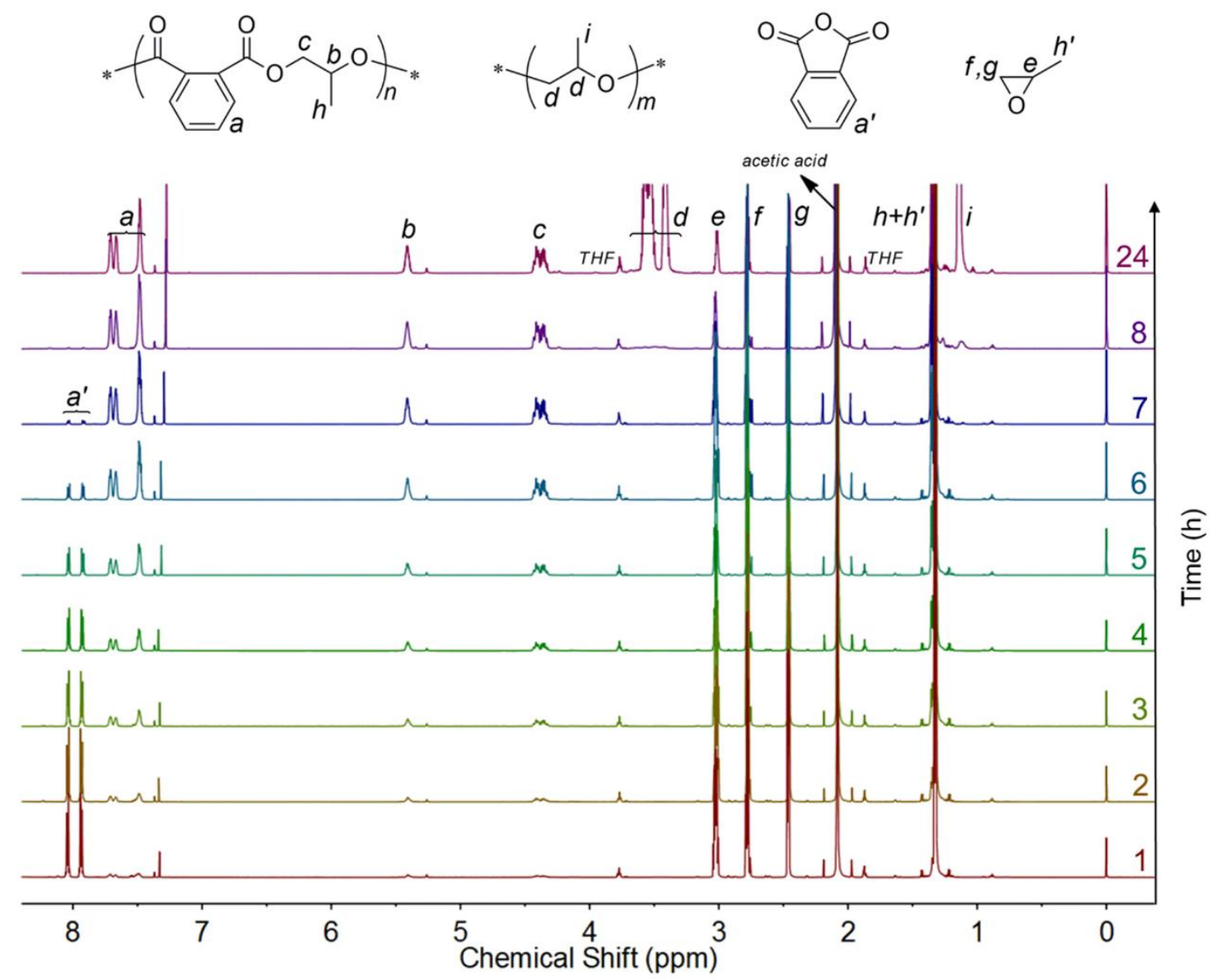

Figure S6. ${ }^{1} \mathrm{H}$ NMR spectra of the aliquots withdrawn at different reaction times from the copolymerization of PA and PO performed in bulk at RT with BDM as the initiator and the feed ratio of $[\mathrm{PA}]_{0} /[\mathrm{PO}]_{0} /[\mathrm{OH}]_{0} /[t-$ $\left.\mathrm{BuP}_{1}\right] /\left[\mathrm{Et}_{3} \mathrm{~B}\right]$ being 50/500/1/0.5/0.25 which leads to a PPO- $b$-P(PA-alt-PO)- $b$-PPO triblock copolymer (PAPO-2 in Table 1). 


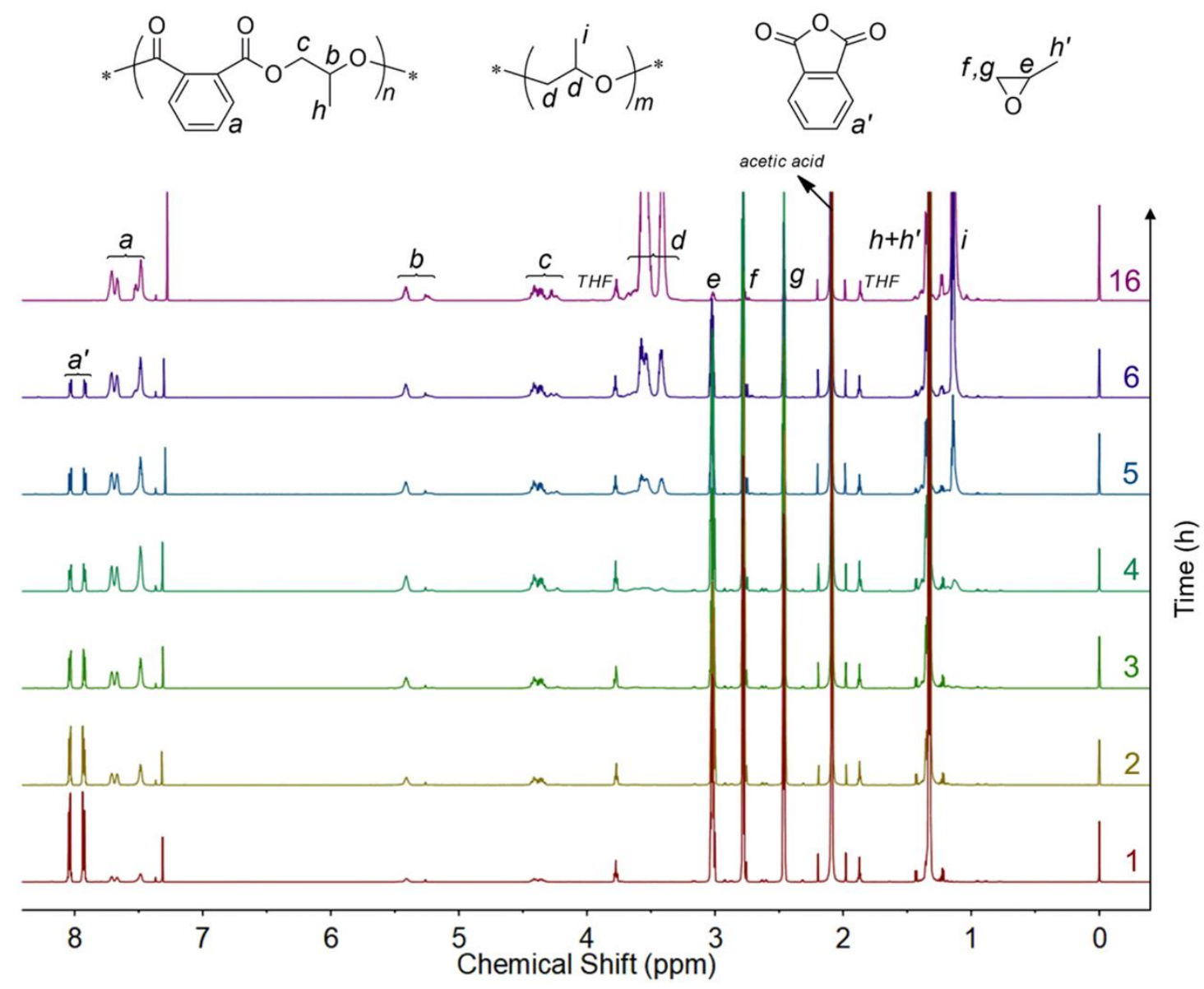

Figure S7. ${ }^{1} \mathrm{H}$ NMR spectra of the aliquots withdrawn at different reaction times from the copolymerization of PA and PO performed in bulk at RT with $\mathrm{BDM}$ as the initiator and the feed ratio of $[\mathrm{PA}]_{0} /[\mathrm{PO}]_{0} /[\mathrm{OH}]_{0} /[t$ $\left.\mathrm{BuP}_{1}\right] /\left[\mathrm{Et}_{3} \mathrm{~B}\right]$ being 50/500/1/0.5/0.5 which leads to a tapered copolymer with $\mathrm{P}(\mathrm{PA}-$ alt $-\mathrm{PO})$ in the middle and PPO enriched at both ends (PAPO-S1 in Table S1). 


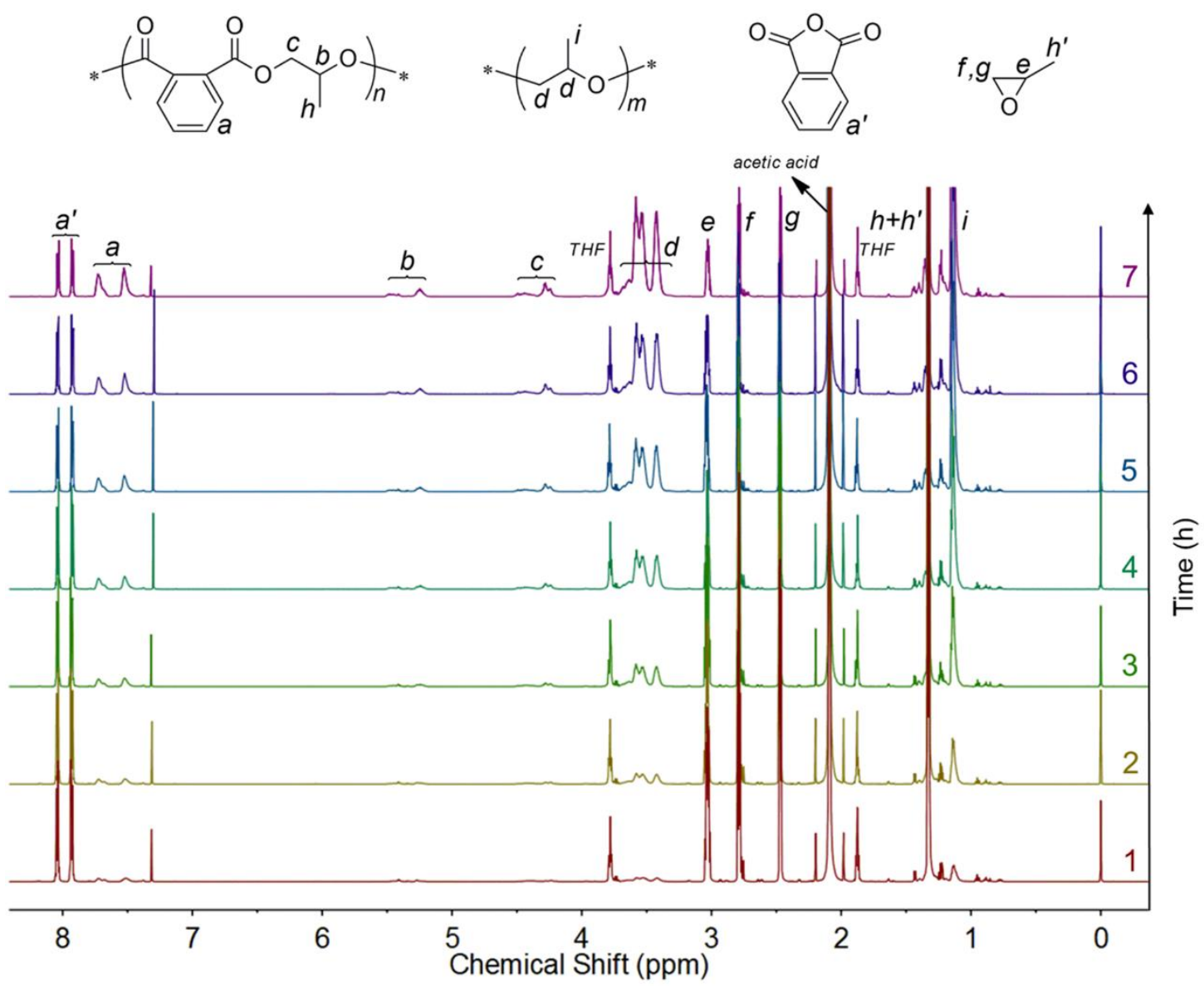

Figure S8. ${ }^{1} \mathrm{H}$ NMR spectra of the aliquots withdrawn at different reaction times from the copolymerization of PA and PO performed in bulk at RT with BDM as the initiator and the feed ratio of $[\mathrm{PA}]_{0} /[\mathrm{PO}]_{0} /[\mathrm{OH}]_{0} /[t$ $\left.\mathrm{BuP}_{1}\right] /\left[\mathrm{Et}_{3} \mathrm{~B}\right]$ being 50/500/1/0.5/1.5 which leads to a gradient copolymer enriched with PPO and featured by gradual decreases of the content of PA-PO units from the middle to both ends (PAPO-S2 in Table S1). 


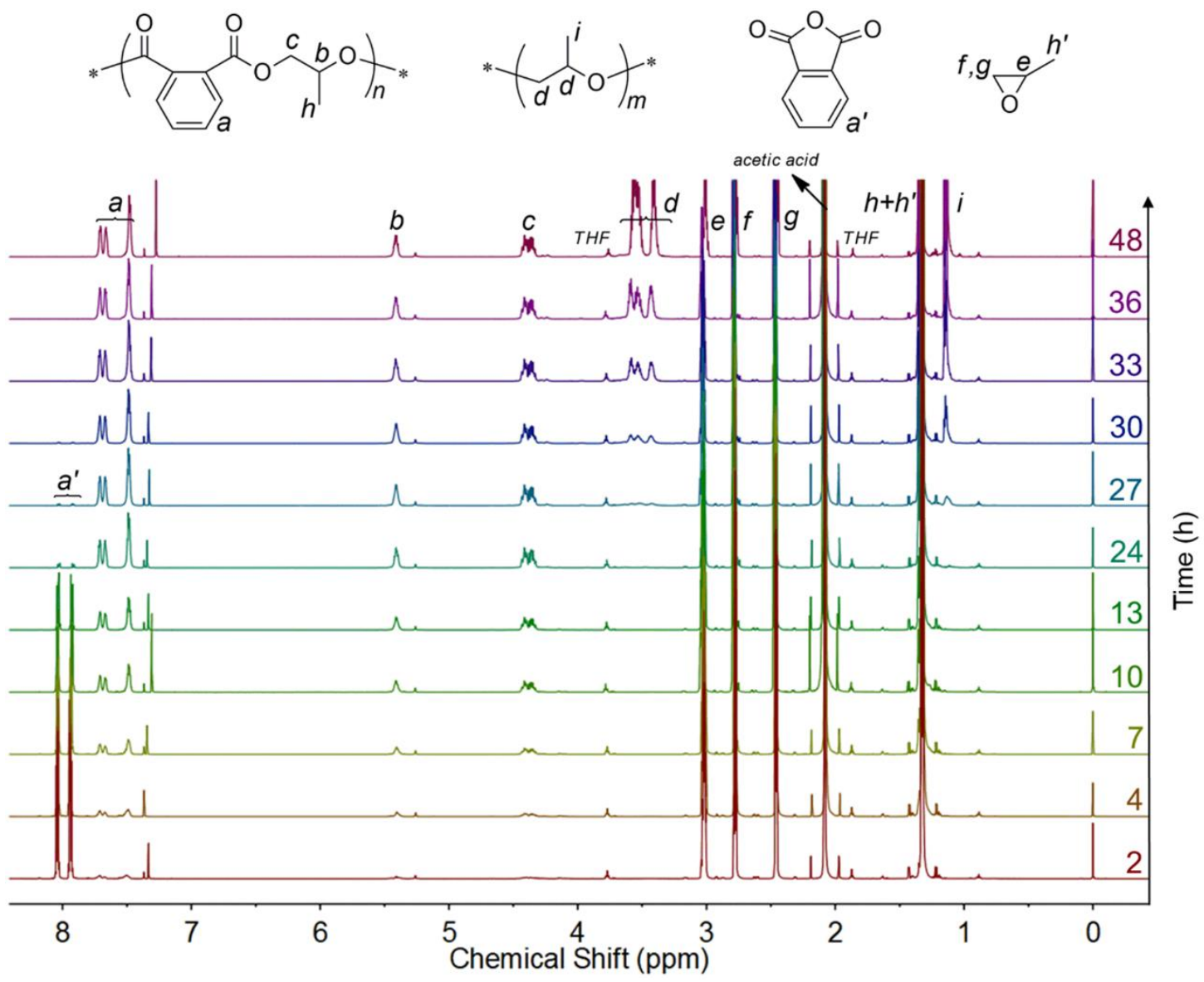

Figure S9. ${ }^{1} \mathrm{H}$ NMR spectra of the aliquots withdrawn at different reaction times from the copolymerization of PA and PO performed in bulk at RT with BDM as the initiator and the feed ratio of $[\mathrm{PA}]_{0} /[\mathrm{PO}]_{0} /[\mathrm{OH}]_{0} /[t-$ $\left.\mathrm{BuP}_{1}\right] /\left[\mathrm{Et}_{3} \mathrm{~B}\right]$ being 50/500/1/0.1/0.15 which leads to a PPO- $b$-P(PA-alt-PO)- $b$-PPO triblock copolymer (PAPO-3 in Table 1). 

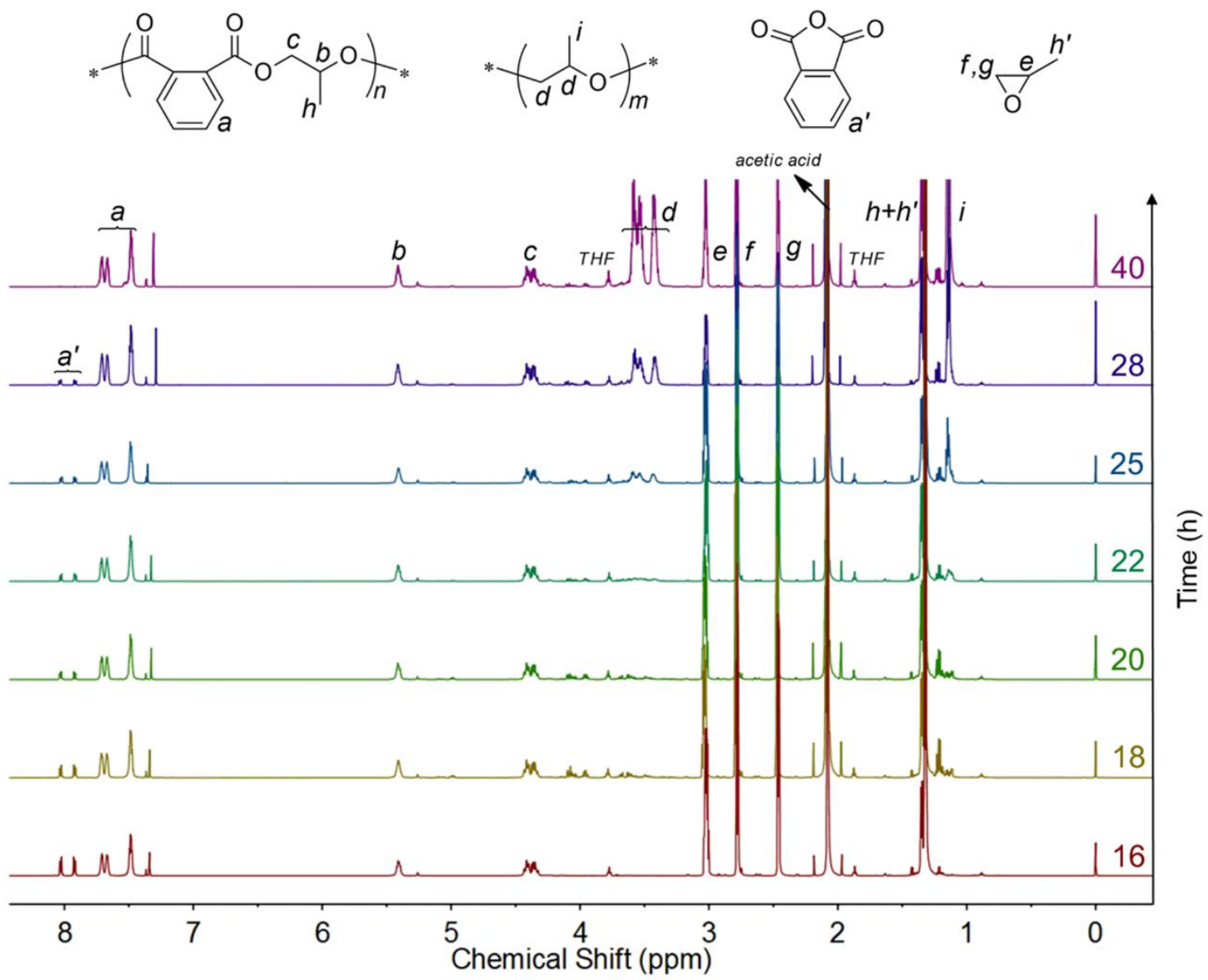

Figure S10. ${ }^{1} \mathrm{H}$ NMR spectra of the aliquots withdrawn at different reaction times from the copolymerization of PA and PO performed in bulk at RT with BDM as the initiator and the feed ratio of $[\mathrm{PA}]_{0} /[\mathrm{PO}]_{0} /[\mathrm{OH}]_{0} /\left[t-\mathrm{BuP}_{1}\right] /\left[\mathrm{Et}_{3} \mathrm{~B}\right]$ being $50 / 500 / 1 / 0.1 / 0.2$ which leads to a tapered block copolymer with $\mathrm{P}(\mathrm{PA}-$ alt-PO) in the middle and PPO enriched at both ends (PAPO-S3 in Table S1). 


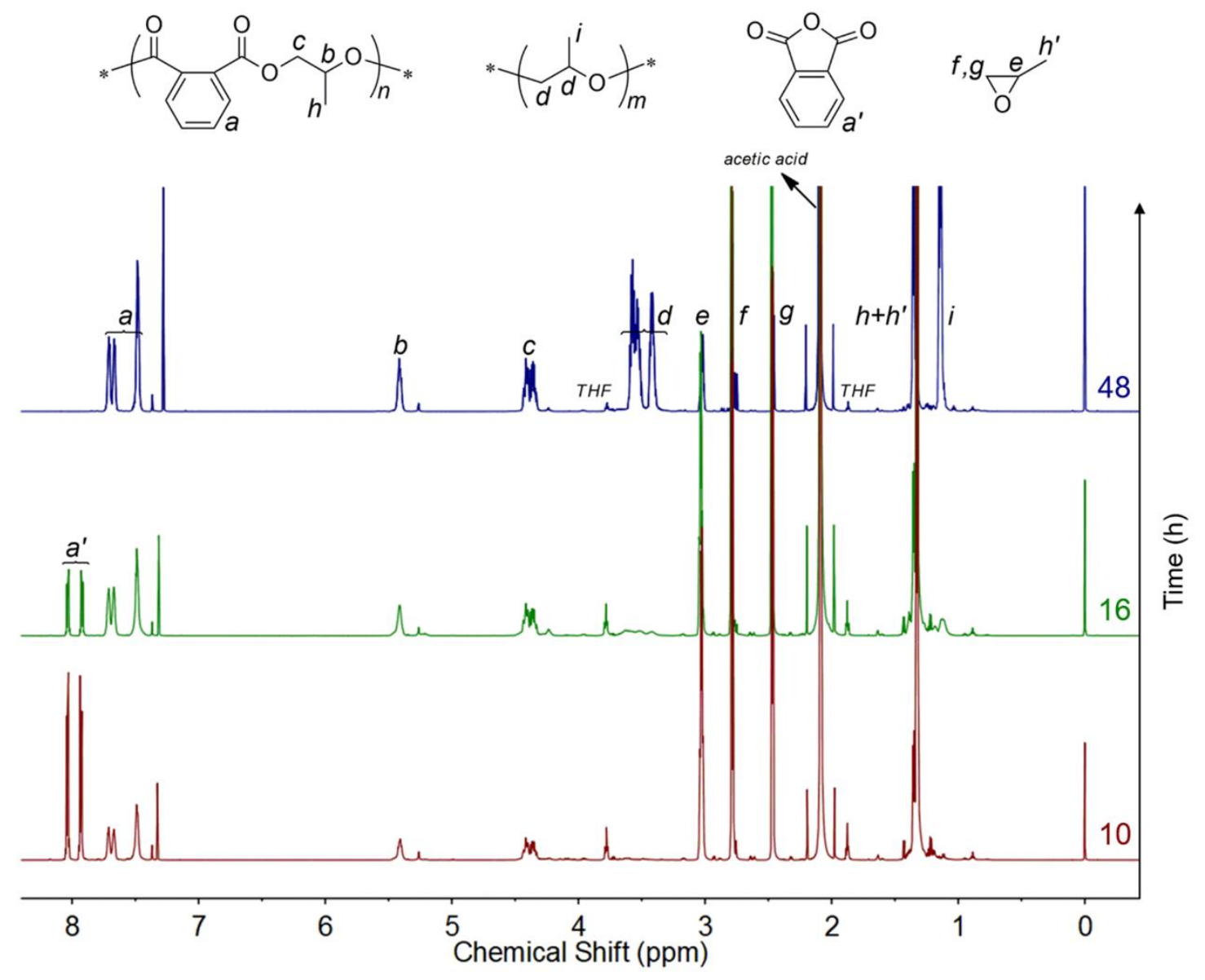

Figure S11. ${ }^{1} \mathrm{H}$ NMR spectra of the aliquots withdrawn at different reaction times from the copolymerization of PA and PO performed in bulk at RT with BDM as the initiator and the feed ratio of $[\mathrm{PA}]_{0} /[\mathrm{PO}]_{0} /[\mathrm{OH}]_{0} /\left[t-\mathrm{BuP}_{1}\right] /\left[\mathrm{Et}_{3} \mathrm{~B}\right]$ being $50 / 500 / 1 / 0.1 / 0.3$ which leads to a tapered copolymer with $\mathrm{P}(\mathrm{PA}-$ alt-PO) in the middle and PPO enriched at both ends (PAPO-S4 in Table S1). 

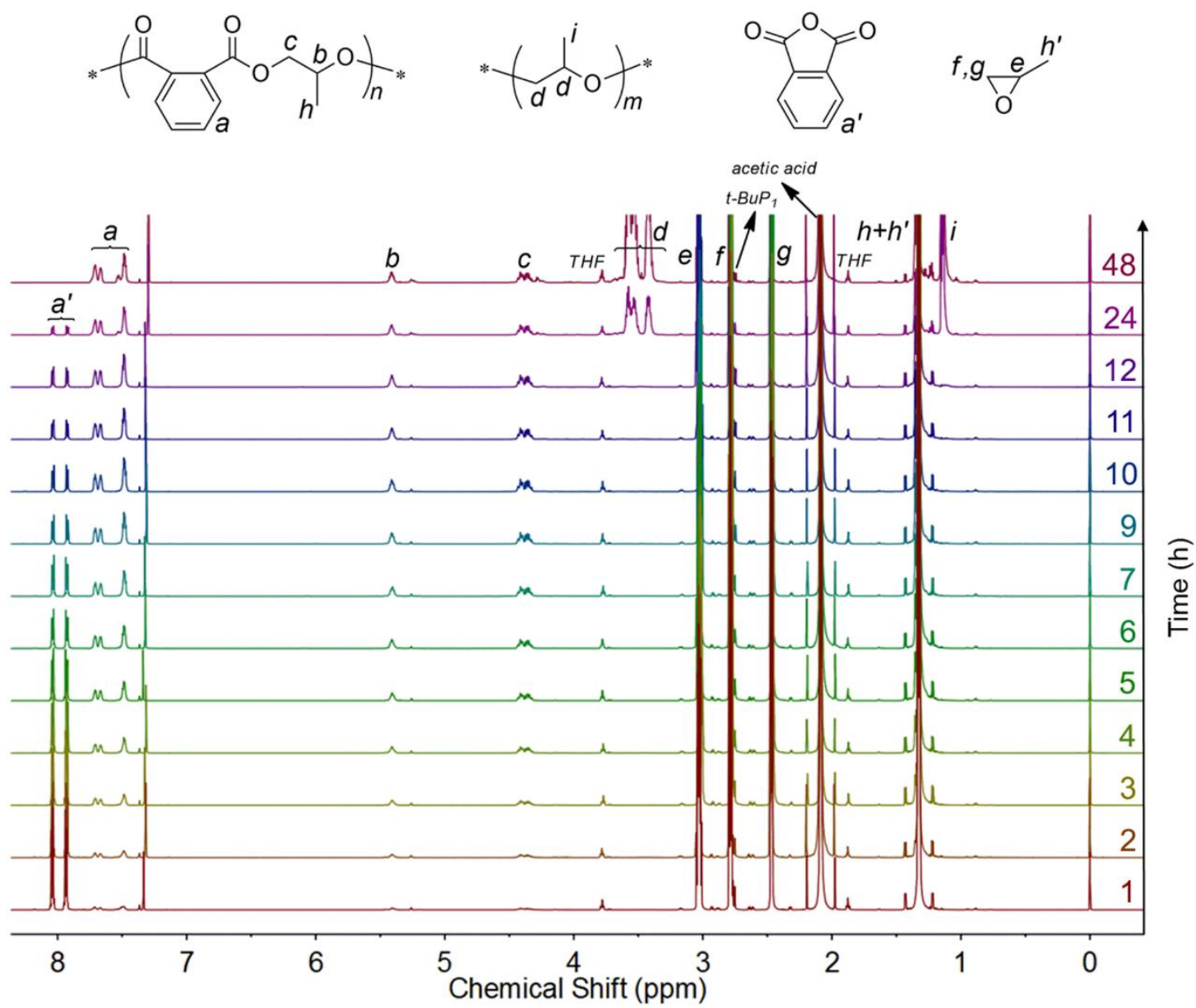

Figure S12. ${ }^{1} \mathrm{H}$ NMR spectra of the aliquots withdrawn at different reaction times from the copolymerization of PA and PO performed in bulk at RT with BDM as the initiator and the feed ratio of $[\mathrm{PA}]_{0} /[\mathrm{PO}]_{0} /[\mathrm{OH}]_{0} /\left[t-\mathrm{BuP}_{1}\right] /\left[\mathrm{Et}_{3} \mathrm{~B}\right]$ being $50 / 1000 / 1 / 0.5 / 0.25$ which leads to a tapered copolymer with $\mathrm{P}(\mathrm{PA}-$ alt-PO) in the middle and PPO enriched at both ends (PAPO-S5 in Table S1). 

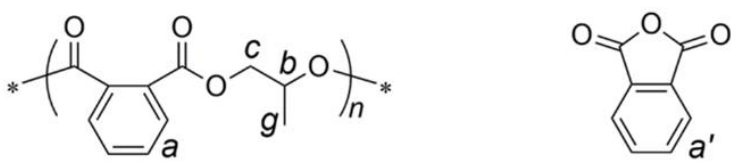

$e, \underbrace{d}_{0} g^{g}$

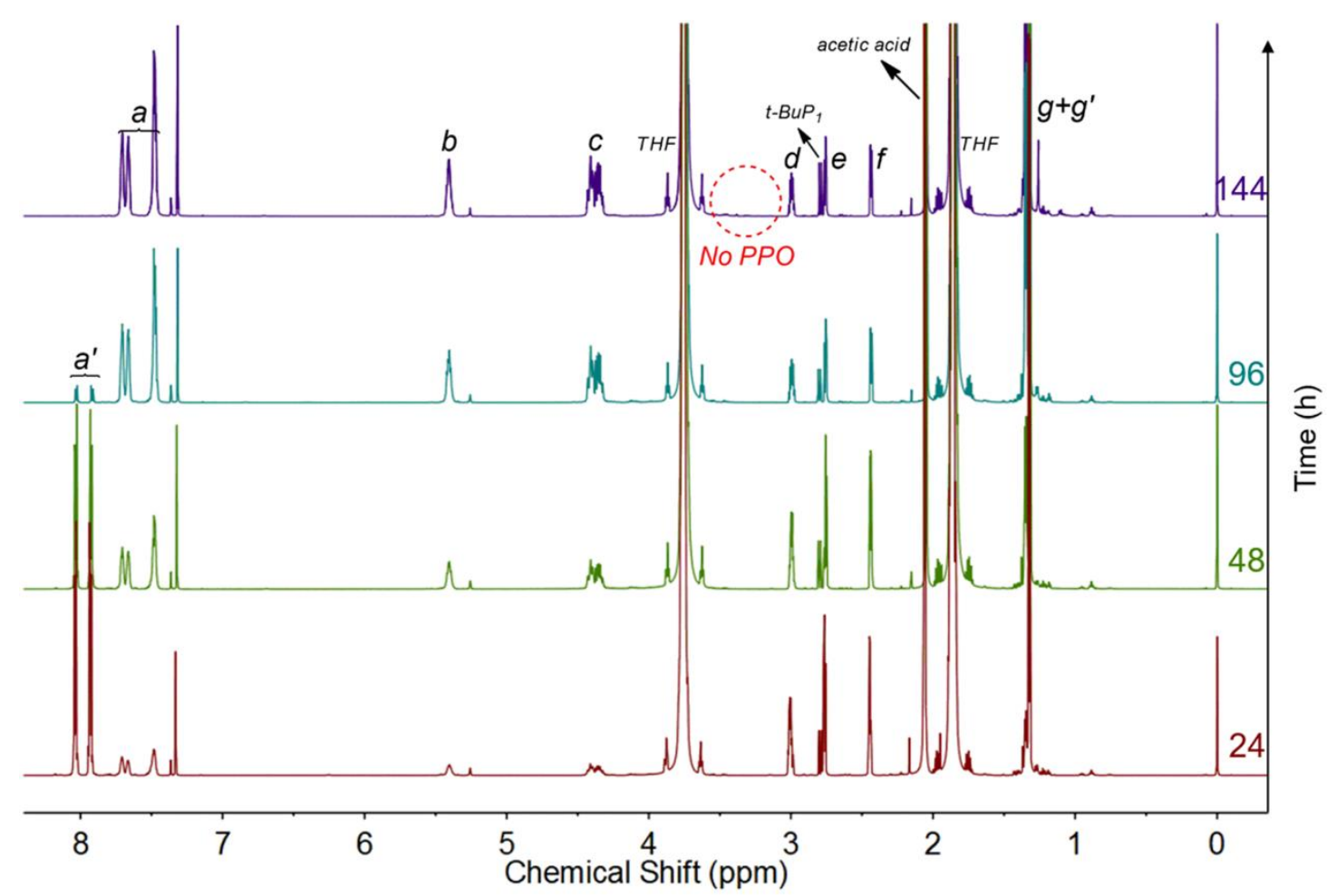

Figure S13. ${ }^{1} \mathrm{H}$ NMR spectra of the aliquots withdrawn at different reaction times from the copolymerization of PA and PO performed in THF at RT with BDM as the initiator and the feed ratio of $[\mathrm{PA}]_{0} /[\mathrm{PO}]_{0} /[\mathrm{OH}]_{0} /\left[t-\mathrm{BuP}_{1}\right] /\left[\mathrm{Et}_{3} \mathrm{~B}\right]$ being 50/75/1/0.5/0.25 $\left([\mathrm{PA}]_{0}=0.9 \mathrm{M}\right)$ which leads to a $\mathrm{P}(\mathrm{PA}-$ alt-PO) alternating copolymer (PAPO-S6 in Table S1). No PPO is formed even at prolonged reaction time after full consumption of PA. 

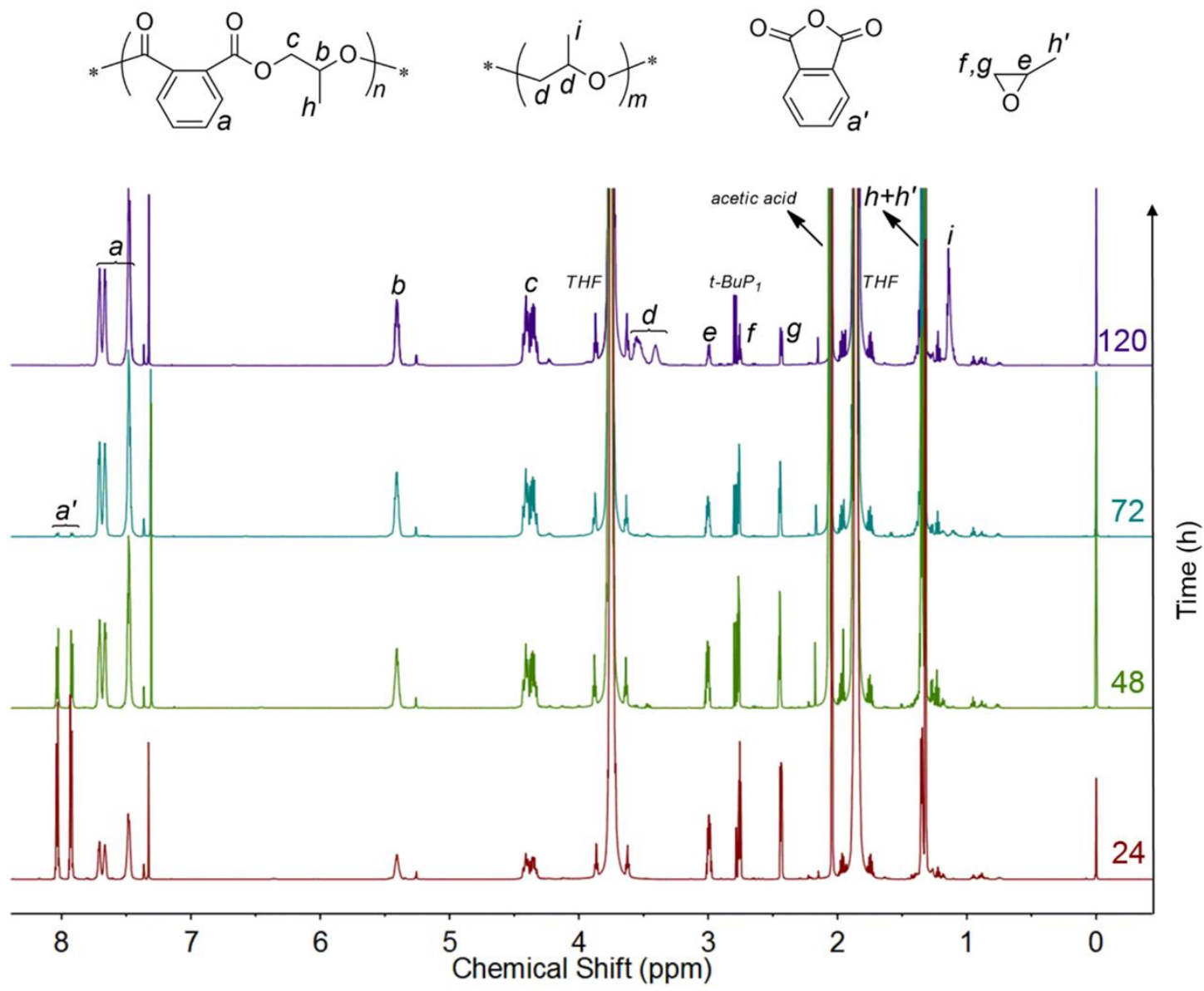

Figure S14. ${ }^{1} \mathrm{H}$ NMR spectra of the aliquots withdrawn at different reaction times from the copolymerization of PA and PO performed in THF at RT with BDM as the initiator and the feed ratio of $[\mathrm{PA}]_{0} /[\mathrm{PO}]_{0} /[\mathrm{OH}]_{0} /\left[t-\mathrm{BuP}_{1}\right] /\left[\mathrm{Et}_{3} \mathrm{~B}\right]$ being $50 / 75 / 1 / 0.5 / 1.5\left([\mathrm{PA}]_{0}=0.9 \mathrm{M}\right)$ which leads to a PPO- $b-\mathrm{P}(\mathrm{PA}-$ altPO)-b-PPO triblock copolymer (PAPO-4 in Table 1; short PPO blocks). 


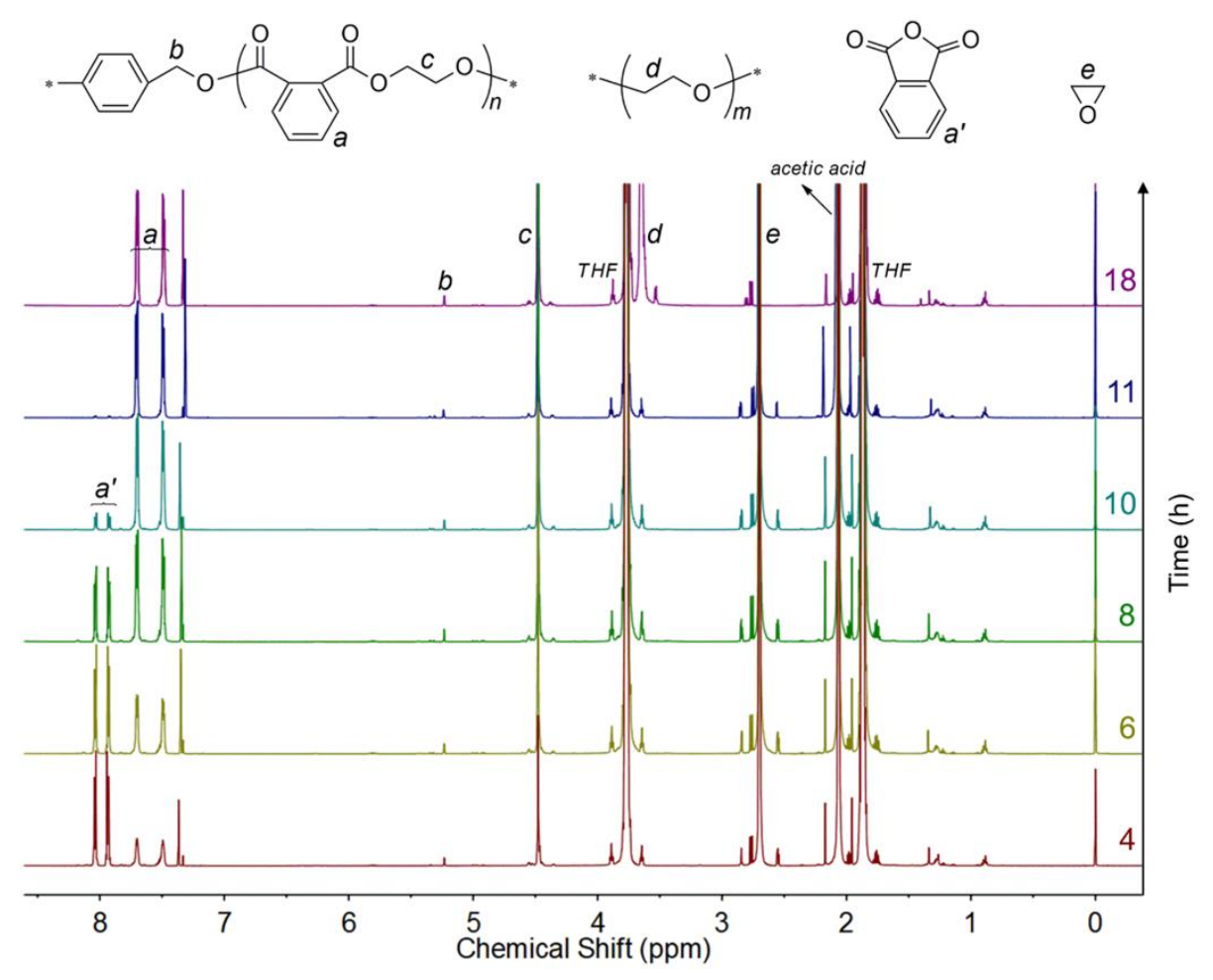

Figure S15. ${ }^{1} \mathrm{H}$ NMR spectra of the aliquots withdrawn at different reaction times from the copolymerization of PA and EO performed in THF at RT with BDM as the initiator and the feed ratio of $[\mathrm{PA}]_{0} /[\mathrm{EO}]_{0} /[\mathrm{OH}]_{0} /\left[t-\mathrm{BuP}_{1}\right] /\left[\mathrm{Et}_{3} \mathrm{~B}\right]$ being $50 / 500 / 1 / 0.5 / 0.15\left([\mathrm{PA}]_{0}=0.7 \mathrm{M}\right)$ which leads to a PEO- $b-\mathrm{P}(\mathrm{PA}-$ alt-EO)- $b$-PEO triblock copolymer (PAEO-1 in Table 1). Conversions of PA and EO in Table 1 are calculated as $a /\left(a+a^{\prime}\right)$ and $d /(d+e)$.

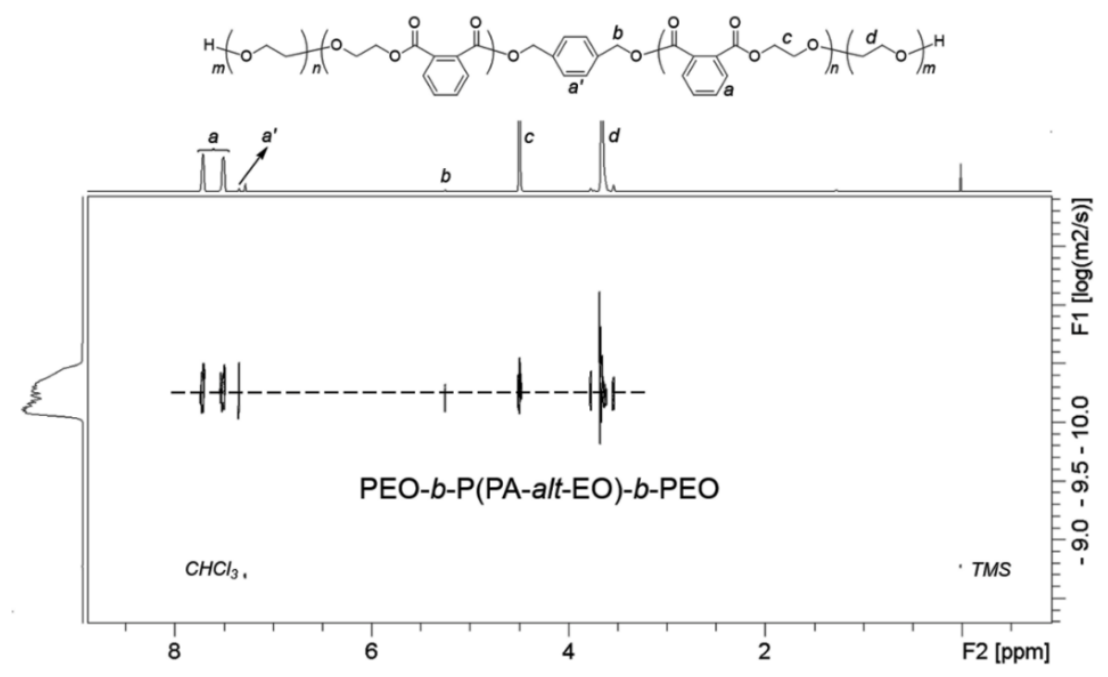

Figure S16. ${ }^{1} \mathrm{H}$ DOSY NMR spectrum of the isolated PEO- $b$-P(PA-alt-EO)- $b$-PEO triblock copolymer onestep synthesized from a mixture of PA and EO with BDM as the initiator (product of PAEO-1 in Table 1). 

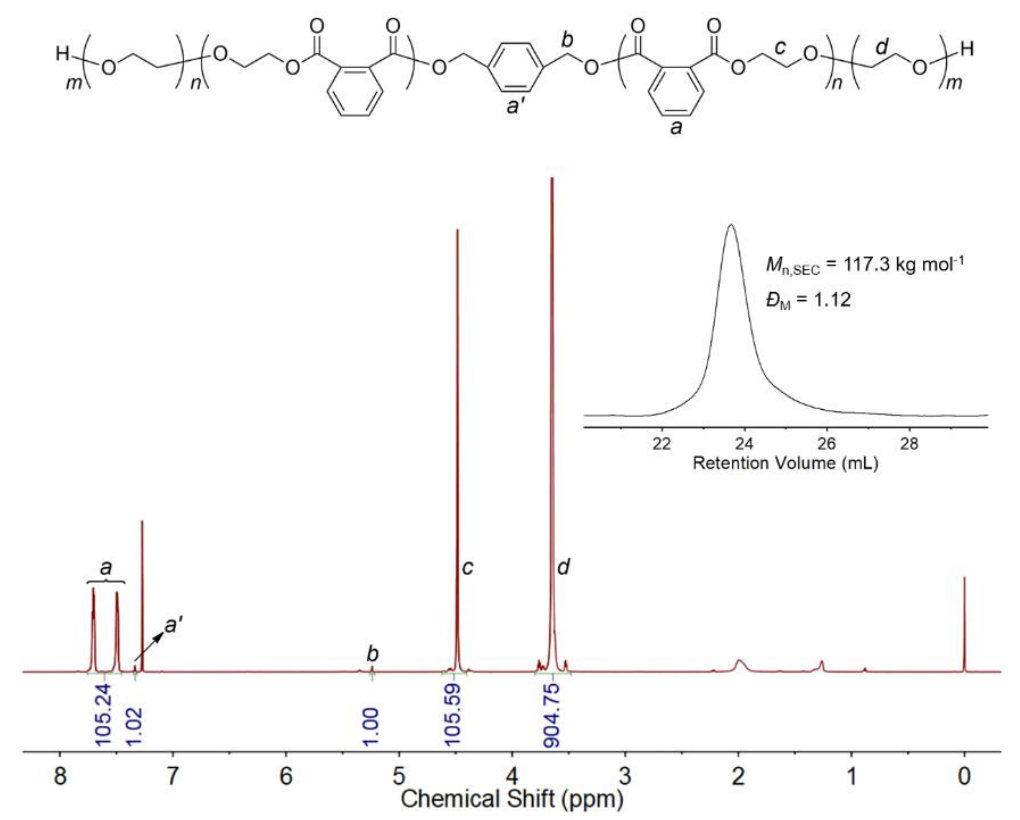

Figure S17. ${ }^{1} \mathrm{H}$ NMR spectrum (isolated product) and SEC traces (inset; crude product) of the PEO- $b$-P(PA$a l t$-EO)- $b$-PEO triblock copolymer one-step synthesized from a mixture of PA and EO with BDM as the initiator (the product of PAEO-1 in Table 1).
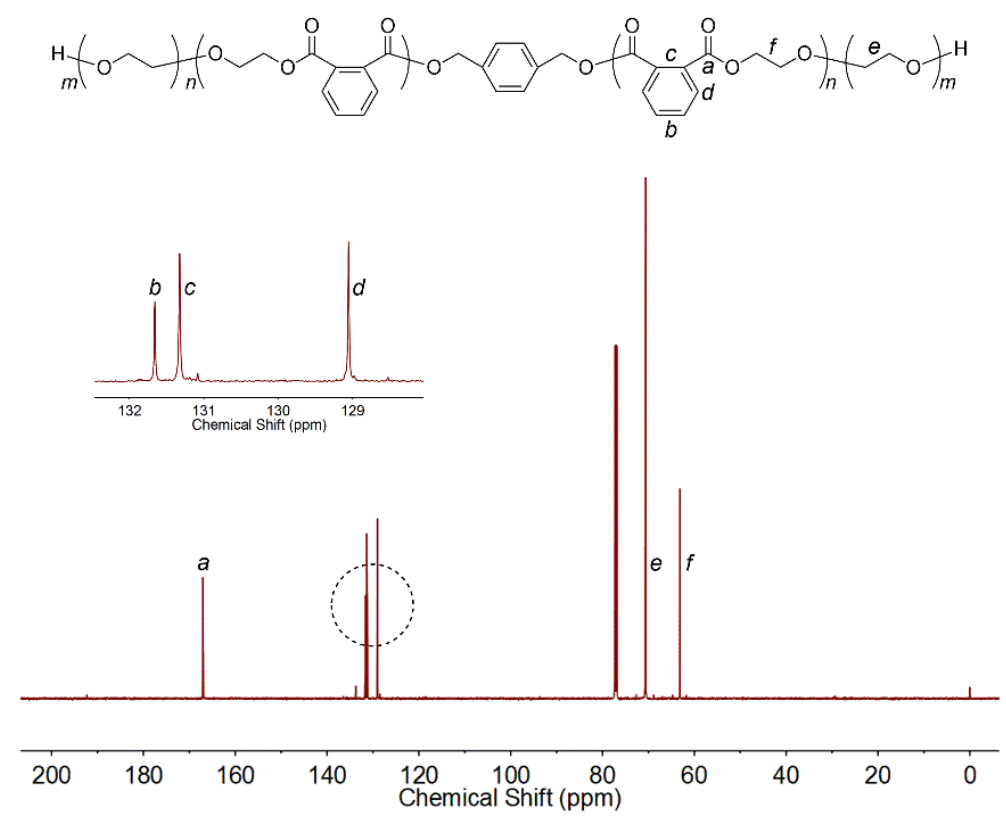

Figure S18. ${ }^{13} \mathrm{C}$ NMR spectrum of the isolated PEO- $b$-P(PA-alt-EO)- $b$-PEO triblock copolymer one-step synthesized from a mixture of PA and EO (the product of PAEO-1 in Table 1). 


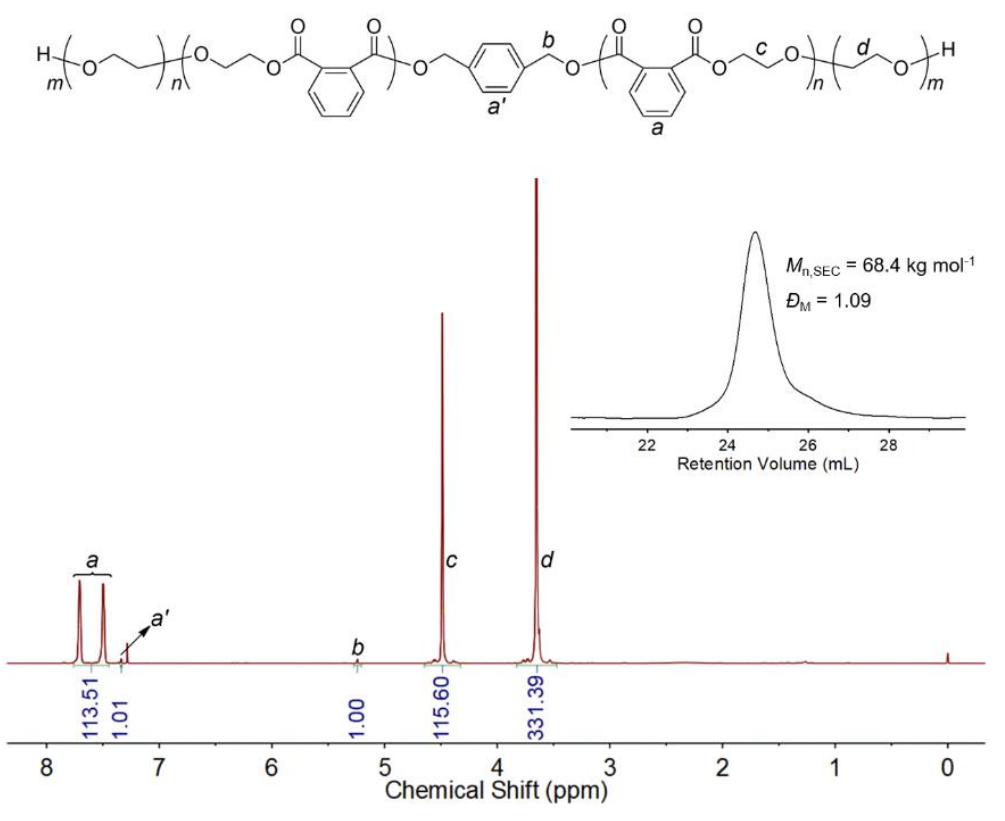

Figure S19. ${ }^{1} \mathrm{H}$ NMR spectrum (isolated product) and SEC traces (inset; crude product) of the PEO- $b$-P(PA$a l t$-EO)- $b$-PEO triblock copolymer one-step synthesized from a mixture of PA and EO with BDM as the initiator (PAEO-2 in Table 1).
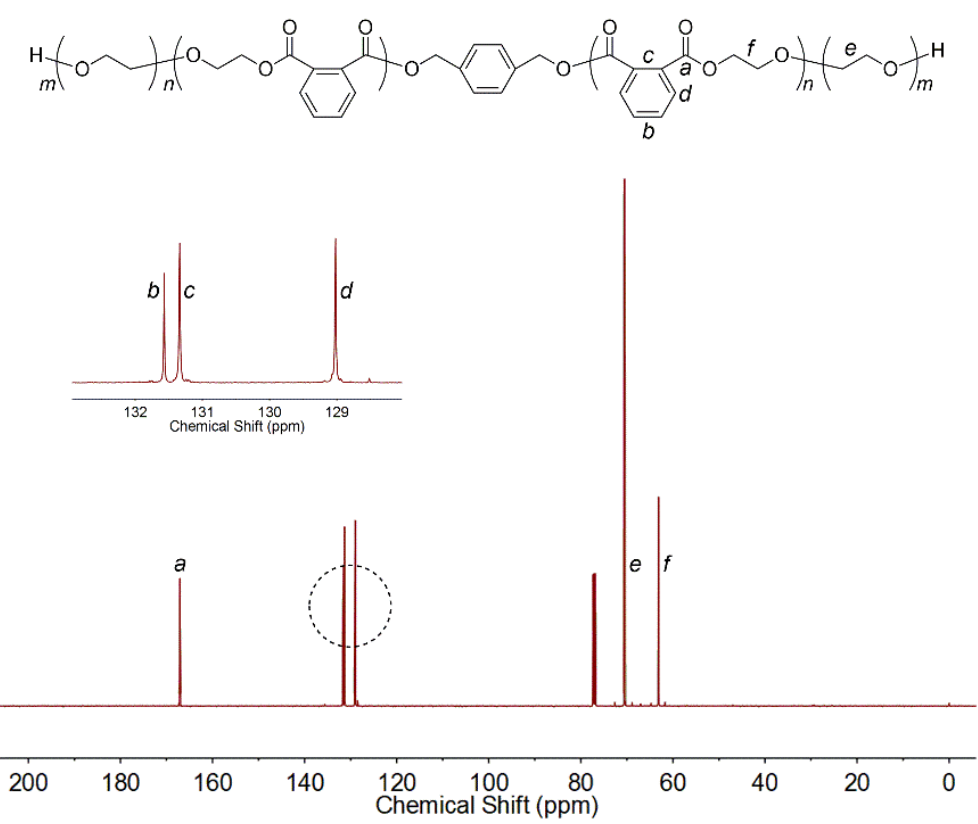

Figure S20. ${ }^{13} \mathrm{C}$ NMR spectrum of the isolated PEO- $b$-P(PA-alt-EO)- $b$-PEO triblock copolymer one-step synthesized from a mixture of PA and EO with BDM as the initiator (PAEO-2 in Table 1). 


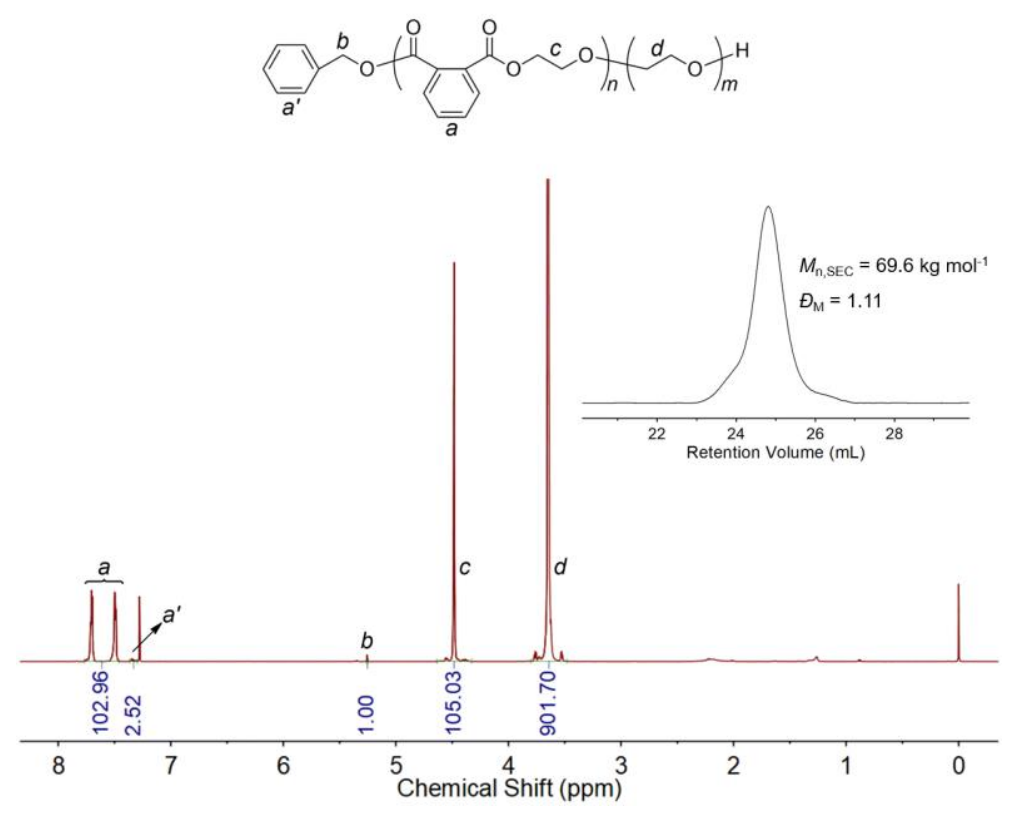

Figure S21. ${ }^{1} \mathrm{H}$ NMR spectrum (isolated product) and SEC traces (inset; crude product) of the P(PA-altEO)- $b$-PEO diblock copolymer one-step synthesized from a mixture of PA and EO with BA as the initiator (PAEO-3 in Table 1).
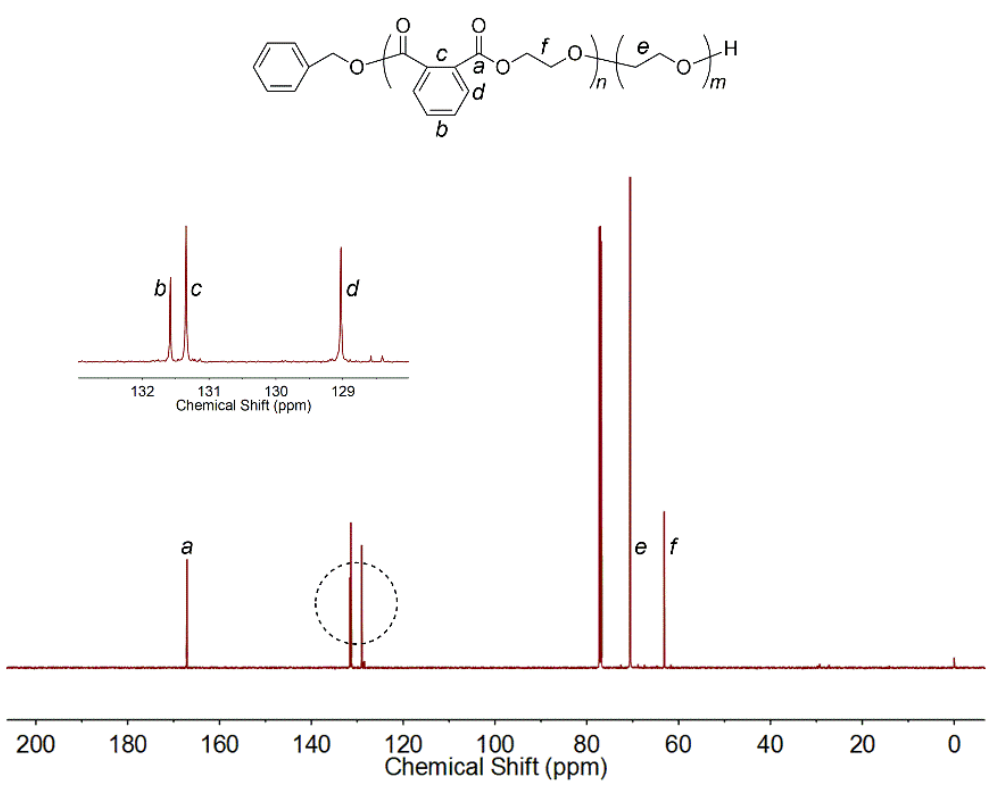

Figure S22. ${ }^{13} \mathrm{C}$ NMR spectrum of the isolated $\mathrm{P}(\mathrm{PA}$-alt-EO)- $b$-PEO diblock copolymer one-step synthesized from a mixture of PA and EO with BA as the initiator (PAEO-3 in Table 1). 


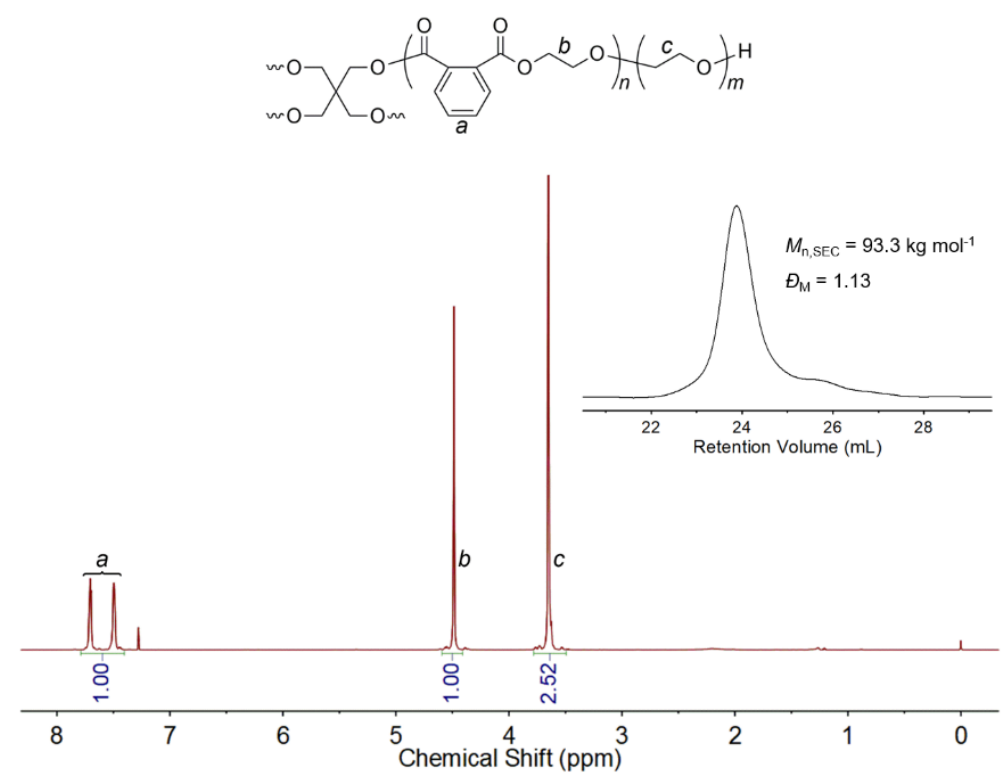

Figure S23. ${ }^{1} \mathrm{H}$ NMR spectrum (isolated product) and SEC traces (inset; crude product) of the [(PA-altEO)- $b$-PEO $]_{4}$ four-arm star-shaped block copolymer one-step synthesized from a mixture of PA and EO with PT as the initiator (PAEO-4 in Table 1).
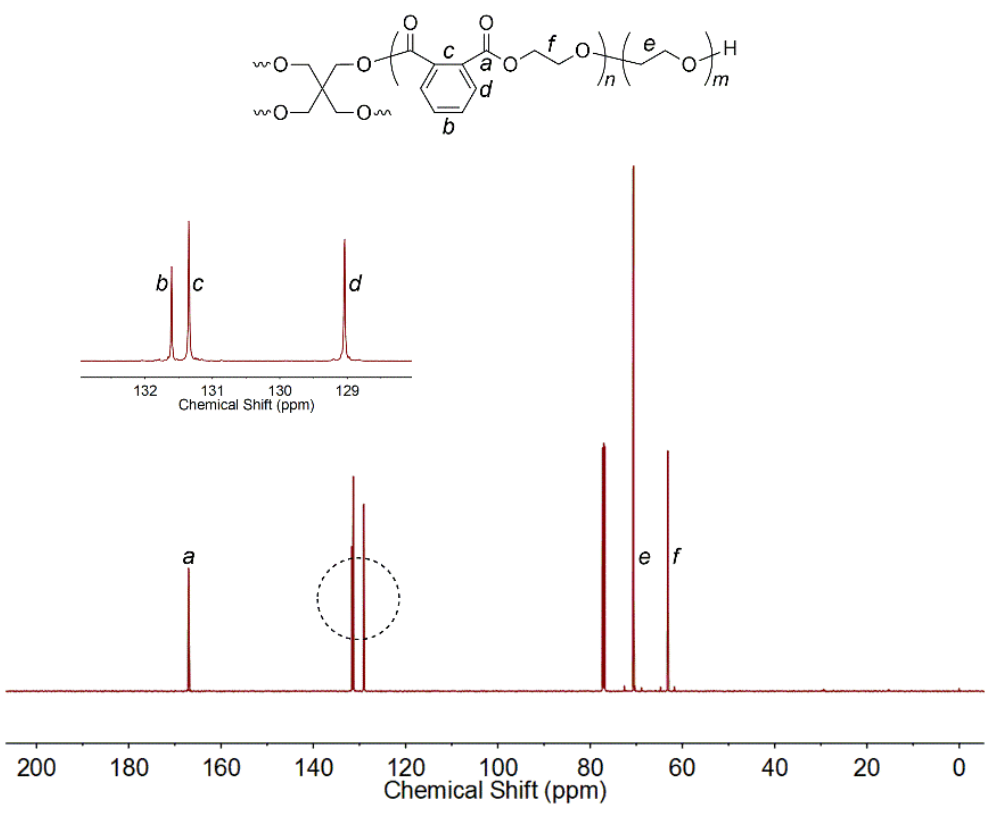

Figure S24. ${ }^{13} \mathrm{C}$ NMR spectrum of the isolated $[(\mathrm{PA}-a l t-\mathrm{EO})-b-\mathrm{PEO}]_{4}$ four-arm star-shaped block copolymer one-step synthesized from a mixture of PA and EO with PT as the initiator (PAEO-4 in Table 1). 

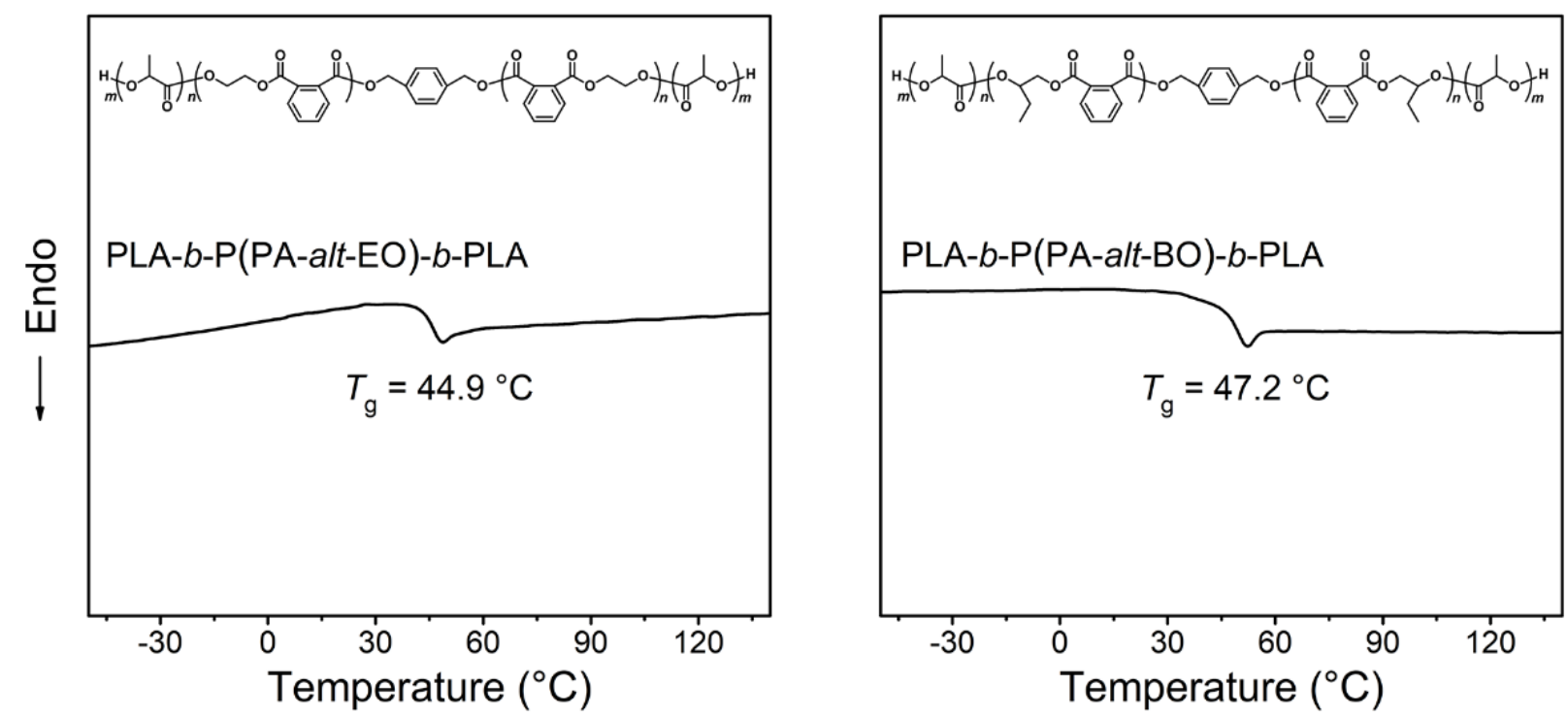

Figure S25. DSC traces (second heating runs) of the triblock copolyesters one-step synthesized in our previous report via $t$ - $\mathrm{BuP}_{1}$-catalyzed sequence-selective terpolymerization of $\mathrm{PA}$, EO or 1,2butylene oxide (BO), and rac-lactide (LA), ${ }^{1}$ i.e. PLA- $b$-P(PA-alt-EO)- $b$-PLA (left) and PLA- $b$ $\mathrm{P}(\mathrm{PA}-a l t-\mathrm{BO})-b$-PLA (right), with BDM as the inititaor. Only one $T_{\mathrm{g}}$ is shown by such block copolyesters which lies between $T_{\mathrm{gS}}$ of PLA $\left(55.0^{\circ} \mathrm{C}\right)$ and $\mathrm{P}\left(\mathrm{PA}-\right.$ alt-EO) $\left(36.1^{\circ} \mathrm{C}\right)$ or P(PA-altBO) $\left(44.0^{\circ} \mathrm{C}\right) .^{2,3}$ 


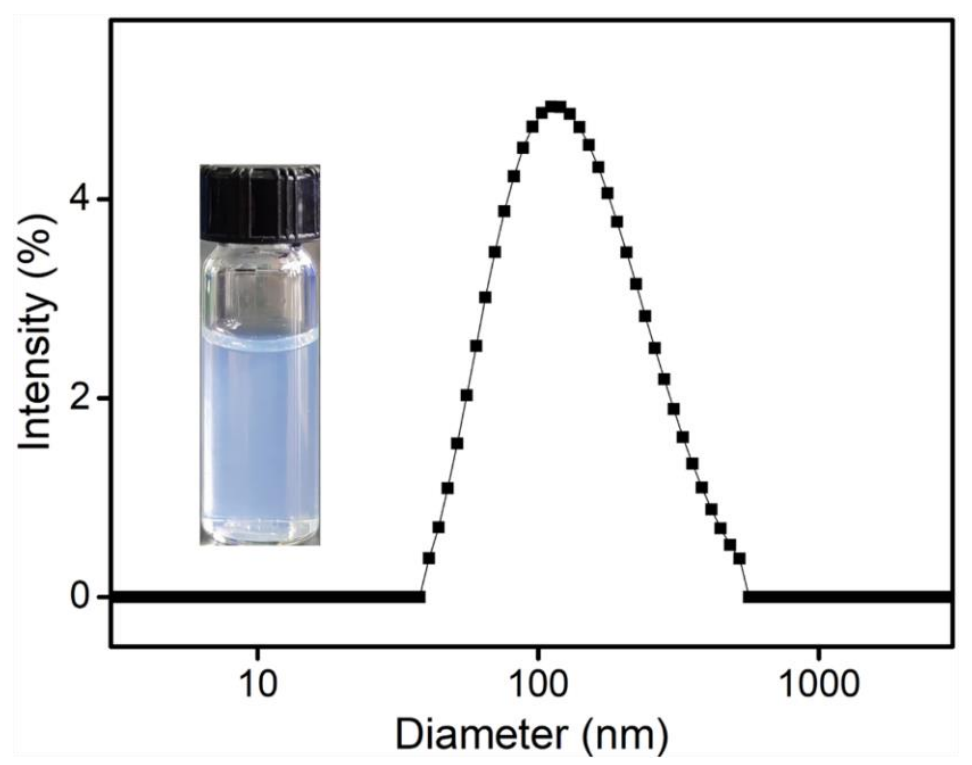

Figure S26. DLS result (distribution of diameter) of the aggregates formed by a one-step synthesized amphiphilic PEO-b-P(PA-alt-EO)- $b$-PEO triblock copolymer (product of PAEO-1 in Table 1) in water at $25{ }^{\circ} \mathrm{C}$ (concentration of polymer $=10.0 \mathrm{mg} \mathrm{mL}^{-1} ; R_{\mathrm{h}}=57 \mathrm{~nm}$ ). Inset is a picture of the solution taken by a digital camera.

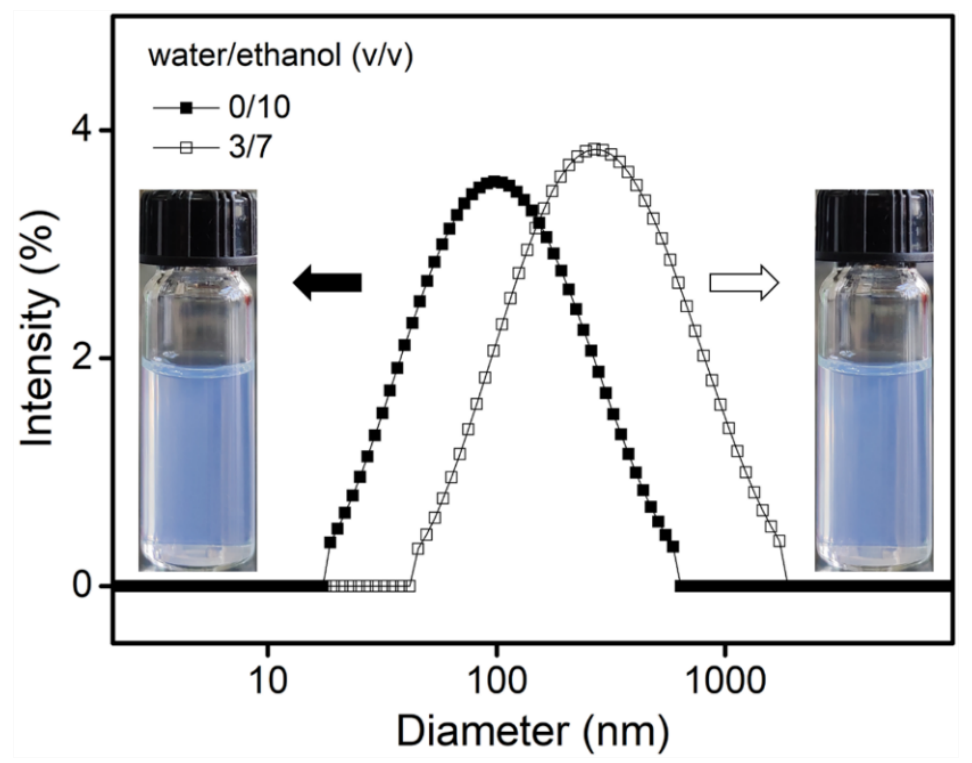

Figure S27. DLS results (distributions of diameter) of the aggregates formed by a one-step synthesized PPO- $b$-P(PA-alt-PO)- $b$-PPO triblock copolymer (PAPO-1 in Table 1) in ethanol and an ethanol-water mixture $(7 / 3, \mathrm{v} / \mathrm{v})$ at $25{ }^{\circ} \mathrm{C}$ (concentration of polymer $=10.0 \mathrm{mg} \mathrm{mL}^{-1} ; R_{\mathrm{h}}=42 \mathrm{~nm}$ and $114 \mathrm{~nm}$ ). Insets are the pictures of solutions taken by a digital camera. 


\section{References}

(1) Li, H.; Luo, H.; Zhao, J.; Zhang, G., Sequence-Selective Terpolymerization from Monomer Mixtures Using a Simple Organocatalyst. ACS Macro Lett. 2018, 7, 1420-1425.

(2) Li, H.; Luo, H.; Zhao, J.; Zhang, G., Well-Defined and Structurally Diverse Aromatic Alternating Polyesters Synthesized by Simple Phosphazene Catalysis. Macromolecules 2018, 51, 2247-2257.

(3) Lim, L. T.; Auras, R.; Rubino, M., Processing Technologies for Poly(lactic acid). Prog. Polym. Sci. 2008, 33, 820-852. 